\title{
Increased pathogenicity of the nematophagous fungus Drechmeria coniospora following long-term laboratory culture.
}

Damien Courtine, Xing Zhang and Jonathan J. Ewbank

Aix Marseille Univ, CNRS, INSERM, CIML, Turing Centre for Living Systems, Marseille, France

Corresponding author: ewbank@,ciml.univ-mrs.fr

ORCID: 0000-0002-9162-0111 (DC), 0000-0001-9847-2193 (XZ), 0000-0002-1257-6862 (JJE)

\begin{abstract}
Domestication provides a window into adaptive change. Over the course of 2 decades of laboratory culture, a strain of the nematode-specific fungus Drechmeria coniospora became more virulent during its infection of Caenorhabditis elegans. Through a close comparative examination of the genome sequences of the original strain and its more pathogenic derivative, we identified a small number of non-synonymous mutations in protein-coding genes. In one case, the mutation was predicted to affect a gene involved in hypoxia resistance and we provide direct corroborative evidence for such an effect. The mutated genes with functional annotation were all predicted to impact the general physiology of the fungus and this was reflected in an increased in vitro growth, even in the absence of $C$. elegans. While most cases involved single nucleotide substitutions predicted to lead to a loss of function, we also observed a predicted restoration of gene function through deletion of an extraneous tandem repeat. This latter change affected the regulatory subunit of a cAMP-dependent protein kinase. Remarkably, we also found a mutation in a gene for a second protein of the same, protein kinase A, pathway. Together, we predict that they result in a stronger repression of the pathway for given levels of ATP and adenylate cyclase activity. Finally, we also identified mutations in a few lineage-specific genes of unknown function that are candidates for factors that influence virulence in a more direct manner.
\end{abstract}

\section{Introduction}

Drechmeria coniospora is a nematophagous Ascomycetes fungus that lies on a distal branch of the Ophiocordycipitaceae ( $\mathrm{Li}$ et al., 2021). It is one of the best-characterised fungal pathogens of Caenorhabditis elegans. Infection starts with the adhesion of non-motile asexual spores (conidia) to the nematode cuticle. These single-celled haploid spores are 
formed through a phialidic mode of holoblastic conidiogenesis. In other words, they grow out from a conidiogenic hypha, on specialized stalks called conidiophores, with their extension involving the complete cell wall of the hypha, and can be distinguished from the conidiogenic hypha before they separate from it. They are also called mitospores, as they are generated through mitosis, with no meiosis, and are therefore genetically identical to their haploid parent. After adhesion, an appressorium forms, allowing the nematode cuticle to be penetrated. Haploid and septate endozoic hyphae grow throughout the infected host, with new conidiophores then emerging through the cuticle of the nematode, forming conidia that can go on to infect other nematodes (Gernandt and Stone, 1999; Saikawa, 1982; Wyatt et al., 2013).

A variety of isolates from diverse locations worldwide exist, including ATCC 96282, derived from a strain collected in Sweden by H.-B. Jansson in 1990 (Jansson and Friman, 1999). This strain has been extensively used in studies addressing host defences (Dierking et al., 2011; Labed et al., 2012; Lee et al., 2010, 2018). More recently, taking its genome as a starting point, $D$. coniospora has been developed as a model to understand how nematophagous fungi can infect and kill their hosts. This capacity has emerged multiple times during evolution and in each case appears largely to involve distinct molecular mechanisms (Andersson et al., 2014; Ji et al., 2020; Lebrigand et al., 2016; Lin et al., 2018; Meerupati et al., 2013; Wang et al., 2018; Xie et al., 2016), although there is also evidence in some cases for convergent evolution (Iqbal et al., 2018).

With regards $D$. coniospora, as a first example, presumably as a consequence of horizontal gene transfer, the fungus has acquired genes encoding proteins containing one or more SapA domains that bind to and potentially inhibit the antimicrobial activity of host SapB-domains proteins (Lebrigand et al., 2016). Secondly, D. coniospora has an unusually broad repertoire of enterotoxins (Wang et al., 2018). Only two out of these 23 enterotoxins have been characterised in any detail. They play specific, partly antagonistic roles, interfering with host defence signalling pathways (Zhang et al., 2021). These examples represent a tiny fraction of the hundreds of potential virulence factors encoded within the D. coniospora genome. A substantial proportion of them are either lineage-specific or correspond to proteins for which no functional annotation exists in any species (Lebrigand et al., 2016). Many aspects of the biology of $D$. coniospora that are most relevant to its capacity to parasitise worms are therefore poorly characterised.

One powerful way to address the molecular basis of physiological traits is to take advantage of genetic and phenotypic variation between natural populations. The genome of a Danish isolate of D. coniospora has also been sequenced (Zhang et al., 2016), but its genome is very different from that of ATCC 96282 (Courtine et al., 2020), rendering comparative functional analysis challenging. Another approach relies on experimental evolution. Typically, organisms are maintained in a defined environment, with or without applied selective pressures, and the changes that accumulate over time are monitored. The best known such study is one from the Lenski lab, where 12 populations of Escherichia coli have been cultured since 1988 in minimal media by batch culture for more than 60,000 generations (Good et al., 2017; Lenski, 2017). In another long-running experiment, Saccharomyces cerevisiae populations evolved over 3 years, for some 10,000 generations in three environments (Johnson et al., 2021; McDonald, 2019). These and other studies have given 
valuable insights into evolutionary processes. It has been observed repeatedly that populations follow a more-or-less foreseeable path, with the rate that fitness increases slowing down as populations adapt, while the mutation rate remains relatively stable. In comparison to complex and changing natural environments, laboratory culture conditions are designed to be simple and constant. Although it is impossible to predict what exact mutations will arise, selection pressure will generally favour the loss of genes and pathways that are superfluous under the experimental conditions (Kvitek and Sherlock, 2013; McDonald, 2019).

Experimental evolution has also been used to characterise host-pathogen interactions. In the case of $C$. elegans, pioneering studies include a dissection of the role of mating modalities in host resistance (Morran et al., 2011), behavioural responsiveness to bacterial microbes (Schulte et al., 2012), and co-evolutionary studies (Masri et al., 2015). The field continues to be very active (e.g. (Ekroth et al., 2021; White et al., 2020, 2021)). Here, we took advantage of an unintentional domestication experiment. In 1999, we started laboratory culture of the $D$. coniospora ATCC 96282 strain. We recently sequenced the genome of this isolate, which we refer to as Swe1, as well as that of a derived strain, Swe3, cryo-archived in 2018 after almost 2 decades of laboratory culture (Courtine et al., 2020). As we show here, there is a notable difference in the speed at which Swe1 and Swe3 kill C. elegans.

Leveraging the genome annotation available for the Swe1 derivative Swe2, cryo-archived and sequenced in 2013 (Lebrigand et al., 2016), we were able to annotate the Swe1 and Swe3 genomes. This then provided an opportunity to conduct a comparative genomic analysis, to identify the mutations that have accumulated over the years, including those potentially linked to the observed increase in virulence. When the laboratory culture of $D$. coniospora was started, there was little expectation that it would continue for so long. Had this been the case, a more controlled experimental protocol would have been instigated, with, for example, passaging of spores at more regular intervals, and replicate populations grown in parallel to be able to determine the robustness and reproducibility of any observed changes. Nevertheless, this single somewhat uncontrolled long-term experiment does provide insight into the evolutionary changes that occurred during domestication of $D$. coniospora and that impact its virulence

\section{Methods}

\section{C.elegans strains and culture}

The strain IG463 ( $r r f-3(b 26) ; f r I s 7)$ was made by standard crosses between the conditionally sterile mutant strain DH26 rrf-3(b26) II (formerly fer-15) and the reporter strain IG274 $(+; f r I s 7$ [nlp-29p::GFP, col-12p::DsRed] IV (Pujol et al., 2008). N2 and other strains were maintained on nematode growth media (NGM) and fed E. coli strain OP50 (Stiernagle, 2006). IG463 and DH26 were maintained at $15^{\circ} \mathrm{C}$, the permissive temperature, the other strains at $25^{\circ} \mathrm{C}$. 


\section{D. coniospora culture}

D. coniospora was serially cultured by infecting C. elegans. Typically, spores were harvested from infected worms every one or two weeks and used to infect a fresh worm population. The methods used are described in detail elsewhere (Powell and Ausubel, 2008). Briefly, about $300 \mu \mathrm{l}$ of freshly harvested spore solution (ca. $1-5 \times 10^{8}$ spores) was added to a standard 10 cm NGM agar plate with 1000-2000 synchronized L4 or young adult N2 worms on an extensive lawn of E. coli OP50. After drying under a laminar flow hood, the plate was incubated at $25^{\circ} \mathrm{C}$ for 1 day. Infected worms were harvested with $50 \mathrm{mM} \mathrm{NaCl}$ and transferred to an NGM plate supplemented with $15 \mu \mathrm{g} / \mathrm{ml}$ gentamicin and $100 \mu \mathrm{g} / \mathrm{ml}$ ampicillin, without OP50. The plate was incubated at $25^{\circ} \mathrm{C}$ for up to 1 week and then stored at $20^{\circ} \mathrm{C}$.

\section{Infection assays}

Spores were harvested from plates at $25^{\circ} \mathrm{C}$ after 6 days and counted using a Neubauer chamber (Bürker) as described (http://www.lo-laboroptik.de/englisch/info/info.html) before dilution in $50 \mathrm{mM} \mathrm{NaCl}$ to the required concentration. Around 150 young adult IG463 worms that had been grown at $25^{\circ} \mathrm{C}$, the non-permissive temperature, were manually transferred to 4 $\mathrm{cm}$ plates containing NGM agar seeded with E. coli OP50. Freshly harvested spores $\left(1 \times 10^{9}\right)$ were spread on the plate. After drying under a laminar flow hood, and overnight infection at $25^{\circ} \mathrm{C}$, for each experimental condition, 25 worms were picked into 4 wells of a 12-well plate containing NGM agar seeded with E. coli OP50. Images of each well were collected automatically every 24 minutes using a custom system that will be described elsewhere. The images were examined, and worms scored as dead when they no longer exhibited movement between successive images.

\section{Analyses with the Biosort worm sorter}

Fluorescent protein expression was quantified with the COPAS (Complex Object Parametric Analyzer and Sorter) Biosort system (Union Biometrica, Holliston, MA) as described (Pujol et al., 2008). Worms were analyzed for length (assessed as TOF, time of flight), optical density (assessed as extinction) and Green and/or Red fluorescence (GFP/Red). Raw data were filtered on the TOF for adult worms (typically $300 \leq$ TOF $\leq 1500$ ). Statistical significance was determined using an unpaired t-test (GraphPad Prism).

\section{Monitoring fungal growth}

Spores (typically $10^{6}$ in $30 \mu \mathrm{l}$ ) were added to each well of 12 -well plates containing $700 \mu \mathrm{l}$ of NGM agar supplemented with $0 \mathrm{mM}, 1 \mathrm{mM}$, or $2 \mathrm{mM} \mathrm{CoCl}_{2}$ and incubated at $25^{\circ} \mathrm{C}$. Fungal growth was recorded using an Zeiss Axio Observer Z1 microscope equipped with Definite Focus, a motorised stage, a PeCon $\mathrm{GmbH}$ incubation chamber and a Hamamatsu C11440-42U30 camera. All images from a stack were aligned using the ImageJ macro Align_Slice (https://github.com/landinig/IJ-Align_Slice/) to compensate for any image drift. Spore and hyphae length were measured using the ImageJ toolbox HyphaTracker v1.0 (Brunk et al., 2018; Schindelin et al., 2012). The thresholds to convert images into binary data were 
set automatically, the minimal area was set to 5 pixels and the last frame was selected to be the reference.

\section{Fungal PCR}

Fungal DNA was extracted as previously described (Courtine et al., 2020) from freshly thawed aliquots of the original isolate ATCC 96282, called here Swe1, or its derivatives Swe2 and Swe3, archived and sequenced in 2013 (Lebrigand et al., 2016) and 2018 (Courtine et al., 2020), respectively. Once samples of Swe1, Swe2 or Swe3, which were cryopreserved at $-80^{\circ} \mathrm{C}$, were thawed, their precise culture history before being used in experiments was recorded (number of passages, etc). The identity of the different strains was verified regularly by PCR using primers designed to amplify one locus per chromosome, divergent either between Swe1 and Swe2, or between Swe2 and Swe3. The strains could be distinguished on the basis of the results of PCR amplification: presence or absence of an amplicon, size of an amplicon, or amplicon sequence, depending on the strain and PCR primers used (Supp. Table $\mathrm{S} 1)$. PCR with the indicated primers pairs was also used to produce amplicons from Swe2 genomic DNA, corresponding to regions that were previously poorly defined, that were then sequenced.

\section{Assembling the Swe2 mitochondrial genome}

The genomic reads from Swe2 (SRR1810847) mapping on the Swe1 and Swe3 mitochondrial sequences (Courtine et al., 2020) were extracted and used for a de novo assembly with IDBA-UD v1.1.3-1 using default parameters (Peng et al., 2012). The resulting longest contig was circularised with nucmer (--maxmatch --nosimplify), followed by show-coords (-lrcT) within the package MUMmer v4.0.0b2 (Marçais et al., 2018). This generated a mitochondrial genome that was judged complete on the basis of comparison with available mitochondrial genomic sequences from the closely-related fungi Purpureocillium lilacinum, Tolypocladium inflatum and Tolypocladium cylindrosporum (Supp. Table S2; Supp. Fig. S1).

\section{Scaffolding of Swe2 sequences into chromosomal assemblies}

A previous comparison of Swe1 and Swe3 genomes revealed a chromosomal collinearity. This had allowed the major Swe2 scaffolds to be assembled into 3 chromosomes (Courtine et al., 2020), but omitted smaller scaffolds that included some predicted protein-coding genes (Supp. Table S3). Each of these unincorporated scaffolds was compared to the Swe1 and Swe3 sequences using BLASTN (Altschul et al., 1997). The alignments were visualised using Kablammo (Wintersinger and Wasmuth, 2015), permitting manual assignment of scaffolds containing repeat sequences to unique chromosomal positions, as well as trimming of unaligned regions. The precise insertion position and orientation for each scaffold was determined by manual inspection of a multiple sequence alignment from the 3 genomes using Mauve (Darling et al., 2004). When the precise junctional sequence could not be defined, an $N N N$ sequence was added at either side of each newly inserted scaffold. 


\section{Improving the Swe2 genome sequence}

The reassembled Swe2 genome still included 1,386 regions of sequence undetermined in the original assembly i.e. stretches with one or several consecutives Ns. Sequences $1000 \mathrm{nt} 5$, and 3' to each of these regions were extracted separately from the Swe2 genome and aligned by BLASTN against the Swe1 and Swe 3 genomes. In the simplest case, when unambiguous syntenic alignments revealed regions of defined genome sequence fully conserved between Swe1 and Swe3, the relevant sequence was copied from Swe1/Swe3 and inserted in the place of the undefined region of the Swe2 genome. In cases where the Swe1 and Swe3 sequences had the same length but were not identical, the differences were examined, and only the ones with 10 or less ambiguous positions were retained. These remaining undefined bases were left as $N$ before using the consensus sequence to edit the Swe 2 genome. This resulted in an addition of 41,997 bp of defined sequence. No attempt was made to correct the Swe2 sequence when the corresponding regions in the Swe1 and Swe3 genomes were of different lengths. In some cases, the flanking regions overlapped when aligned, because of an incorrect copy number for a repetitive sequence in the Swe2 genome. We then used the consensus Swe1 and Swe3 sequences to remove this superfluous sequence from the Swe2 genome, representing a total of 7,579 bp of deleted sequence. As a complementary automatic approach, in parallel we used the tool Sealer, from the assembler ABySS (Paulino et al., $2015)$ with the parameters "-b20G -k120 -k110 -k100 -k90 -k80-k70 -k60 -k50 -k40 -F $700-P$ $10-B 3000 "$ to generate a list of gaps to be closed, many of which were also identified by the manual workflow. We filtered these out, as well as those containing ambiguous bases, and then implemented the remaining modifications identified by Sealer. The improved version of Swe2 still contains 33,795 Ns in 993 stretches.

\section{Genome similarity metrics}

Average Nucleotide Identity values were calculated using pyani (v0.2.9) with default parameters (Pritchard et al., 2015). Genomes were aligned with Minimap v2.17-r974-dirty with the parameters $-c--c s=$ long $(\mathrm{Li}, 2018 \mathrm{a})$. The resulting PAF file was converted to MAF with the Minimap2 utility paftools.js view $-f$ maf and the command sed 's $/ \wedge$ a /a score $=\Lambda$. The gap-compressed identity score was extracted from the field de: $f$ in the PAF file, and the gap-excluded identity score was obtained by parsing the MAF alignment (BioPython AlignIO v1.78). For all gap-free positions, the number of matches and mismatches was recorded, allowing the number of matches divided by number of matches and mismatches to be calculated. These metrics were calculated for alignment blocks longer than $1 \mathrm{Mb}(\mathrm{Li}, 2018 \mathrm{~b})$. Homopolymers were removed from the genomes with the command "sed -e 's/[aA $] \backslash\{5, \backslash\} / / \mathrm{g}^{\prime}$

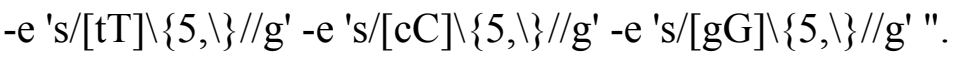

\section{Swe2 gene set}

A number of proteins predicted for D. coniospora ARSEF 6962 (Zhang et al., 2016), referred to here as Dan2, were absent from the original Swe2 protein set as judged by the results of reciprocal BLASTP searches. These included members of highly repeated families, for example integrases and transposases, as well as a few with atypical structures (KYK54054.1/KYK54053.1/KYK56388.1/KYK54065.1)) that we did not attempt to curate. 
The remaining Dan2 protein sequences were aligned by TBLASTN against the Swe2 genome. Those matching an existing predicted Swe2 protein-coding gene were considered likely to reflect events of gene expansion in Dan2 and not pursued further, with the exception of genes encoding proteins with an enterotoxin alpha domain (PFAM: PF01375), which was the subject of manual annotation (Zhang et al., 2021). Then Dan2 protein sequences that aligned with predicted coding sequence from Swe2 with an identity greater than $90 \%$ and for which the main exon was more than $80 \%$ of the predicted coding sequence for the gene were manually curated and added to the set of predicted protein-coding genes in Swe2. When polishing of the Swe2 genome removed one or more $N$ from a predicted protein-coding gene, the RNAseq reads (SRR1930119, SRR1930124) and/or BLASTX alignment at NCBI against $\mathrm{nr} / \mathrm{nt}$ databases were used to validate the corrected sequence.

\section{Gene Comparison}

To identify the mutations that accumulated within protein-coding genes, the Swe 2 gene set was directly compared to the Swe1 and Swe3 genome sequences, taking advantage of their conserved genomic structure. Thus, from the start of each chromosome, Swe 2 genes were sequentially aligned on Swe1 and Swe3 by BLASTN v2.8.1+ with the parameters -max_hsps 1 -dust no, verifying at each iteration that the target gene was in the expected chromosomal position. For each such gene, the query coverage, percent of identity, as well as alignment start and stop coordinates on the Swe1 and Swe3 chromosomes were recorded.

We then selected, i) genes with a query coverage equal to 1 and less than $100 \%$ sequence identity, ii) genes with a query coverage different from 1 . For the former set, exons for each gene were aligned to the expected gene sequence in Swe1 and Swe3 by BLASTN to identify genes with mutations in introns; these were excluded from further analysis. The protein sequence of the remaining genes was aligned to Swe1 and Swe3 by TBLASTN with parameters -seq no and -subject_loc to define the gene coordinates on the target genome. All high scoring pairs (HSPs) were compared 2 by 2 between Swe1 and Swe3 to identify potential sequence changes. The predicted protein sequence of candidate genes with expected non-synonymous substitutions were aligned on the expected Swe1/Swe3 gene using Exonerate v2.2.0 (Slater and Birney, 2005) and parameters - $m$ protein2genome to confirm the mutation. Finally, the sequence evidence for each potentially mutated position was checked in the 3 genomes using the sets of short-reads available: ERR3997395, SRR1810847 and ERR3997392 for Swe1, Swe2 and Swe3, respectively, and only those fully supported were retained. The second set of genes was parsed in the same way, except for those having one or more exons that failed to align during the first BLASTN analysis. Among these, genes with $N$ in their sequence were removed. For the remaining genes, each corresponding genomic locus in the 3 Swe genomes was manually inspected in combination with alignments of short sequencing reads as above, and long reads (ERR3997483, ERR3997394) for Swe1 and Swe3, respectively and only those exhibiting fully supported non-synonymous changes were retained. 


\section{Results}

\section{D. coniospora has become more virulent following laboratory culture}

We have cultured $D$. coniospora in the laboratory for two decades, passaging it serially through C. elegans hundreds of times. We noticed that compared to the original isolate, which we call Swe1, the passaged strain, Swe3, appeared to kill its nematode host more rapidly. As D. coniospora can be cryopreserved at $-80^{\circ} \mathrm{C}$, we were able to compare in the same experiment the Swe1 and Swe3 strains. When we thus assayed the survival of $C$. elegans following $D$. coniospora infection, there was indeed a significant difference between the strains ( $\mathrm{TD}_{50} 40.7$ vs $70.8 \mathrm{~h}$ for Swe3 vs Swe1, $\mathrm{p}<0.0001$; Fig. $1 \mathrm{~A}$ ). The speed of killing is influenced by the number of fungal conidia (spores) that attach to the nematode cuticle (Zugasti et al., 2016). Non-infectious spores acquire an adhesive bud as they mature, essential for the capacity to attach to the host. There were no significant differences in spore morphology nor in their rate of maturation between Swe1 and Swe3 (Fig. 1B), with figures that were comparable to those reported previously for D. coniospora (van den Boogert et al., 1992). Nor was there any significant difference for spore attachment to $C$. elegans between the two strains (Fig. 1C), suggesting that the observed difference in worm survival was related to other changes affecting fungal virulence. This was supported by the fact that at early time points during the infection, Swe3 provoked a significantly greater host innate immune reaction, as reflected by the higher expression of the $n l p-29 p:: G F P$ transgene (Fig. 1D), a well-characterised reporter of the host response to fungal infection (Pujol et al., 2008). Additionally, there was markedly more rapid growth of mycelia from infected worms before and after they died from infection with Swe3 compared to Swe1 (Fig. 1E). The greater virulence of Swe3 therefore appears to be correlated with an increase in fungal growth during the colonization of C. elegans.

To investigate whether the difference in virulence might reflect a more general alteration of fitness, we compared the growth of Swe1 and Swe3 in the absence of worms. These tests were conducted in the absence of bacteria, as we observed that the E. coli strain OP50 used with $C$. elegans strongly inhibited fungal growth. Interestingly, Swe3 grew in culture more rapidly than Swe1 (Fig. 1F), suggesting that part of the observed increase in virulence might reflect generally improved growth under laboratory culture conditions, rather than changes affecting specific virulence mechanisms.

\section{Improving the Swe2 genome sequence}

We wished to identify the changes between the Swe1 and Swe3 genomes that could account for their phenotypic differences. The faster growth of Swe3 could reflect changes in mitochondrial function. While the nuclear genome of Swe2, a strain intermediate between Swe1 and Swe3 was sequenced and annotated a few years ago, its mitochondrial genome had not been assembled (Lebrigand et al., 2016). Taking the mitochondrial genomes of Swe1 and Swe3 as a template (Courtine et al., 2020), we remapped the available Swe2 DNA reads, allowing assembly of a complete Swe2 mitochondrial genome. When we compared the genomes of the 3 strains, we found that they were $100 \%$ identical. Thus, the phenotypic 
differences observed between Swe1 and Swe3 must be a consequence of changes to the nuclear genome.

While the Swe1 and Swe3 genomes are more complete than that of Swe2 (Courtine et al., 2020), gene predictions have only been made for Swe2 (Lebrigand et al., 2016). We therefore needed to transpose the Swe2 gene annotations to the other 2 strains' genomic sequences in order to then be able to compare gene sequences between the different strains. Before doing so, we decided to improve the existing Swe2 sequence and gene predictions. Using the most recent chromosome-level assembly (Courtine et al., 2020) as a starting point, we took advantage of the global synteny between the Swe1 and Swe3 genomes to improve further the assembly of the Swe2 nuclear genome, adding 22 previously un-scaffolded small Swe2 scaffolds, for a total of exactly $580 \mathrm{~kb}$ to the existing $31.14 \mathrm{Mb}$ genome (an increase of $0.19 \%$; Supp. Table S3).

At the nucleotide level, the Swe1 and Swe3 genomes are extremely similar, with numerous stretches of $>100 \mathrm{~kb}$ with $100 \%$ sequence identity, the longest being $260 \mathrm{~kb}$. If a particular sequence is absolutely conserved between Swe1 and Swe3, it is reasonable to assume that the Swe2 sequence will be the same. We validated this assumption by amplifying and sequencing 2 randomly selected Swe2 genomic regions containing undetermined (i.e. " $N$ ") nucleotides (Supp. Fig. S2). On this basis, we therefore replaced 19,478 previously undetermined nucleotides in the Swe2 genome with the corresponding sequence from the Swe1/Swe3 genomes, in 471 stretches ranging from 1 to $694 \mathrm{bp}$ (median $23 \mathrm{bp}$ ), thereby adding a further $42 \mathrm{~kb}$ of defined sequence, removing $7.5 \mathrm{~kb}$ of extraneous (erroneously duplicated) sequence, and resulting in an improved sequence for 4 protein coding genes (see Methods for details). This then gave us high-quality chromosomal level assemblies for Swe1, Swe2 and Swe3, that provided a starting point for more detailed analyses.

\section{Sequence divergence following years of laboratory culture}

Unlike the Swe2 genome (Lebrigand et al., 2016), the Swe1 and Swe3 genomes were assembled using long-reads, with short-read polishing. This has the potential to introduce systematic errors, particularly in homopolymeric sequences (Courtine et al., 2020), complicating precise comparisons. Nevertheless, to have a global overview of the sequence divergence between the 3 genomes, we calculated the Average Nucleotide Identity (ANI), a widely applied measure to compare genome sequences, using one alignment-free and two alignment-based methods (Olm et al., 2017). As expected, the sequences were all very similar by this metric (>99.9\%). Surprisingly, however, Swe1 and Swe3 showed a higher sequence similarity to each other than to the intermediary strain Swe2 (Supp. Table S4). Therefore, to complement this analysis and provide a more refined view of the sequence divergence between the 3 Swe strains, we aligned their genomes and evaluated the similarity between each pair. We restricted this test to blocks of sequence that gave unambiguous alignments longer than $1 \mathrm{Mbp}$, to limit the confounding effects of repeated sequences (see Discussion). To obtain an estimate of single nucleotide substitutions, we chose the gap-excluded identity (Li, 2018b). We also used the gap-compressed identity within Minimap2, in which indels of any size are counted as one event. Despite polishing (see above), the Swe2 genome includes stretches of undetermined sequences. We therefore calculated the different metrics with $N$ 
masking when appropriate. The Swe1 and Swe3 genomes were calculated to differ by less than $0.002 \%$, i.e. at one position per $50 \mathrm{~kb}$ (Table 1). This value rose to ca. $0.009 \%$ when indel events were taken into account. Unexpectedly, but consistent with the results obtained with ANI, the metrics indicated that the genomes of Swel and Swe3 were indeed more similar to each other than either were to the genome of Swe2. Compared to the Swe2 genome, the Swe1 and Swe 3 genomes differed by $0.004 \%$ and $0.005 \%$ respectively. When indels were taken into account, these figures increased, up to $0.06 \%$ (Table 1).

Inspection revealed that many instances of potential differences occurred in stretches of homopolymeric sequence. It is known that correctly calling homopolymers from long-reads is challenging. Our analysis indicates that even with short-read polishing (Courtine et al., 2020), the Swe1 and Swe3 genomes contain residual homopolymer errors (Supp. Fig. S3). To have a more realistic measure of sequence similarity, we therefore removed homopolymer sequences of 5 or more identical nucleotides, from each of the Swe genomes, and recalculated the different metrics. In all comparisons, the similarity scores increased, with a more marked effect for comparisons involving Swe2 (Table 1). Nevertheless, Swe1 and Swe3 were still reported to have the highest similarity, with a divergence as low as $0.0005 \%$ and $0.0001 \%$ (i.e. one change per $200 \mathrm{~kb}$ and $1 \mathrm{Mb}$ ) by the gap-excluded and gap-compressed metrics, respectively. The values for the comparison with Swe2 were an order of magnitude higher $(0.004 \%$ and $0.003 \%$ of divergence with Swe1 and Swe3, respectively), and about $0.04 \%$ of divergence using the gap-compressed metric. As discussed below, this likely reflects the different genome sequencing approaches. Nevertheless, the values for Swe1 and Swe3 give an estimate of the comparatively low sequence evolution of the Swe genomes over time.

\section{No sexual reproduction in $D$. coniospora under laboratory conditions.}

Any interpretation of $D$. coniospora molecular evolution requires a knowledge of its reproductive mode. Whether or not $D$. coniospora has a sexual cycle remains unclear. Sexually reproducing fungi can be homothallic (self-fertile) or heterothallic (outcrossing) (Heitman et al., 2007). In ascomycetes, this is determined by the allelic combination of the genes of the mating type (MAT) loci, termed idiomorphs. In a homothallic species, individual cells will possess both MAT1-1 and MAT1-2 idiomorphs, while in heterothallic species, a single cell will have genes of only one idiomorph. Mating is then restricted to cells with complementary idiomorphs. Zhang et al. reported the D. coniospora ARSEF 6962 (called here Dan2) genome to include a well-conserved MAT1-1 locus composed of 3 genes (MAT1-1-1 (KYK59754.1), MAT1-1-2 (KYK59755.1) and MAT1-1-3 (KYK59756.1)), but no MAT1-2 idiomorphs. Taken together with evidence for an active repeat induced point mutation (RIP) system, and the presence of genes for 2 RIP system proteins, as well as 4 heterokaryon incompatibility (HET) proteins, they suggested that $D$. coniospora might be heterothallic (Zhang et al., 2016). Dan2 is a derivative of the D. coniospora isolate CBS 615.82 that we refer to as Dan1 (Courtine et al., 2020). Like Dan2, the Dan1 genome contains genes for the 2 RIP system and 4 HET proteins, as well as 3 MAT1-1 genes in a single locus, but no MAT1-2 genes. While the Swe genomes contain genes for the same RIP system and HET proteins (Supp. Table 5), no MAT genes were predicted in the original annotation of the Swe2 genome (Lebrigand et al., 2016). On the other hand, in the Swe2 region syntenic to the 
Dan1/Dan2 MAT1-1 locus, using BLASTX and TBLASTN searches, we found a putative MAT1-2-1 gene that had not been previously annotated, fully conserved in Swe1 and Swe3, but absent from the Dan1 and Dan2 genomes (Fig. 2). Zhang et al. had proposed that $D$. coniospora's adaptation to an endoparasitic lifestyle might result in a gradual loss of sexual reproduction (Zhang et al., 2016). On the basis of our analysis, while it remains possible that in nature D. coniospora is heterothallic, under our experimental conditions, the Swe strains used here will only reproduce in an asexual manner. Since spore formation involves a transition between two haploid states, with no meiosis, for this study, the D. coniospora isolate Swe1 and its derivatives can be considered to behave as haploid asexual clones.

\section{Completion of the Swe proteome}

The absence of MAT1-2-1 from the predicted gene set for Swe2 suggested that there might be other lacunae in gene prediction. We therefore conducted an all-against-all comparison between the protein-coding genes of Dan2 and Swe2 (Genbank GCA_001625195.1 and GCA_001618945.1, respectively). This identified 298 genes present in Dan2 for which there was no equivalent prediction for Swe2. Detailed sequence searches in the Swe2 genome (see Methods) revealed plausible sequences for 39 of them, and these were added to the Swe2 gene set. This set was then used to predict genes in the Swe1 and Swe3 genomes, using a sequential approach (see Methods). Direct searches of the remaining 259 Dan2 genes against the Swe1 genome failed to identify any further previously unpredicted genes.

\section{Genomic comparison of the $3 D$. coniospora strains reveals mutated genes}

We then compared the respective sequences of the complete set of 8,702 protein-coding genes from the Swe1, Swe2, and Swe3 genomes. The vast majority, 94.7\%, had precisely the same DNA sequence in the 3 genomes (Fig. 3). The remaining 457 genes potentially contain mutations. In most cases (68.4\%), the mutation was present in an intron. In no case did this affect splice donor or acceptor sites and these mutations would not be expected to affect the corresponding protein. We filtered out 103 of the remaining 144 genes either because the mutation was synonymous, and would not result in any change in the sequence of the corresponding protein, or since a potential mutation had been called because the polished Swe2 sequence still contained one or more $N$. Even though the 3 genomes are of high quality, 31 out of the remaining 41 potential mutations were found to be a consequence of an error in a homopolymeric sequence, despite short-read support for the consensus sequence (e.g. Supp. Fig. S3). These errors in the Swe1 and/or Swe3 genomes were manually corrected. It should be noted that similar errors will exist in non-coding regions that were not examined here. In the end, we identified with high confidence just 10 protein-coding genes with indels or non-synonymous mutations in exonic sequences.

When applicable, the changes that we found in the genomic sequence were fully supported by the transcriptomics data available for Swe2. Interestingly, in two cases, specifically for mutations that were predicted to appear between Swe2 and Swe3, the RNAseq reads were indicative of sequence heterogeneity (Supp. Fig. S4). The samples for RNAseq analysis had been collected following a particular culture regime, involving amplification in liquid media (Lebrigand et al., 2016). It appears that the RNAseq captured a snapshot of a heterogeneous 
population, with a mixture of both mutated and non-mutated fungal lineages, prior to subsequent fixation of the respective mutations.

The first example where we captured a mutation before it became the preponderant allele in the population corresponds to g932.t1/ODA82425.1 that encodes a transcription factor related to sterol regulatory element binding proteins (SREBP), homologous to Srel in the fission yeast Schizosaccharomyces pombe. Swe1 and Swe2 share a common sequence, while in Swe3, the gene carries a premature stop codon that would be predicted to be a null mutation (Table 2). Srel is activated under hypoxic and sterol-depleted conditions and upregulates the expression of genes involved in sterol biosynthesis (Hughes et al., 2005). A similar process exists in Aspergillus species, for which the ability to grow under hypoxic conditions is linked to virulence (Chung et al., 2014). In fungi of the classes Sordariomycetes and Leotiomycetes, relatively close phylogenetically to Drechmeria, the homologues of SREBP, such as FgSre 1 in Fusarium graminearum, are required for hypoxic growth, but are not involved in the regulation of sterol biosynthesis, which is controlled by the sterol uptake control protein FgSR (Liu et al., 2019). The gene g932.t1, which we refer to here as DcSre1, is therefore potentially involved in growth under hypoxic and/or sterol-depleted conditions.

While in natural environments sterols can be limited, to support $C$. elegans growth, NGM is supplemented with cholesterol. The loss of DcSrel might have arisen as a consequence of prolonged growth on a sterol replete medium. To address the potential function of DcSrel, we therefore first assayed the growth of Swe3 on agar plates of NGM with or without added cholesterol. We observed no obvious difference between the high and low cholesterol conditions (Supp. Fig. S5). Since even without DcSre1, Swe3 is able to maintain its growth regardless of sterol levels, this suggests that DcSre1, like FgSre1, is not involved in the regulation of sterol biosynthesis. D. coniospora does possess an orthologue of $F g S R$ (ODA81938.1), and we hypothesise that this plays the role of sterol biosynthesis regulator as in closely-related species. On the other hand, when we assayed Swe1 and Swe3 in the presence of $\mathrm{CoCl}_{2}$, which mimics hypoxia (Lee et al., 2007), there was a significant difference in the growth of the two strains. While under standard conditions Swe3 grew faster than Swel (Fig. 1F, Fig. 4A), at a concentration of $1 \mathrm{mM}$ of $\mathrm{CoCl}_{2}$, the situation was reversed and Swe1 clearly grew better than Swe3. Indeed Swe3's growth was as strongly inhibited as it was in the presence of $2 \mathrm{mM} \mathrm{CoCl}_{2}$, when Swel failed to grow too. Thus, presumably as a consequence of the mutation in DcSre 1, Swe3 has lost the capacity to adapt to conditions that mimic hypoxia. Whether loss of DcSrel function also leads to better growth under laboratory conditions, both in the absence of worms and during infection, remains to be determined.

The second gene for which there was evidence for the mutation arising during liquid culture of Swe2 and being fixed in Swe3 was g7915.t1/ODA75859.1 (Table 2). It corresponds to the RPN7 subunit of the proteasome lid, required for the structural integrity of the complex (Isono et al., 2004). We identified a non-synonymous mutation at a highly conserved position within the Pfam RPN7 (PF10602) domain. The proteasome serves an essential role in cell physiology. We would predict this mutation to affect overall organismal fitness rather than being directly important for virulence.

Several other mutations affect genes involved in important cell functions (Table 2). Thus, we identified a nonsense mutation that occurred between Swe2 and Swe3 in the gene g7471.t1/ODA76724.1, encoding a protein similar to hamartin/tuberous sclerosis protein 1 
(TSC1). The TSC1/TSC2 complex has GTPase Activating Protein (GAP) activity and is known to inactivate the Ras GTPase, Rheb (Rhb1/a). In S. pombe, loss of Tsc1 and/or Tsc2 function results in a decreased uptake of arginine and impacts amino acid biosynthesis (van Slegtenhorst et al., 2004). A second mutation, in gene g8020.t1/ODA75964.1, also potentially impacts Ras signalling as a non-synonymous change, N319D, occurred between Swe1 and Swe2 in the D. coniospora Ras gene itself. The mutation is predicted to affect the interaction with the Ras regulator GDP Dissociation Inhibitor that stabilises the inactive (GDP-bound) form of Ras in the cytosol (Müller and Goody, 2018). The mutations observed in DcTscl and DcRas 1 have the potential to affect the overall growth capacity of $D$. coniospora.

Similarly, the predicted null mutation in gene g3500.t1/ODA80732.1 (a single nucleotide insertion causing a frameshift and so a precocious stop codon) affects the $D$. coniospora Bud2p homologue. In S. cerevisiae, Ras-GAP Bud2p activates the Ras protein Rsr1p/Bud1p, which controls the site of budding. Loss of function of Bud2 leads to the constitutive activation of Rsr1p/Bud1p and thus to a random budding site (Ni and Snyder, 2001). In $D$. coniospora, loss of DcBud2 might be expected to affect the pattern of hyphal branching, but the ramifications from a single germinating spore (see for example Figs. 1E, 4B) confounded attempts at quantitative comparison. Nevertheless, again, this is a mutation more likely to affect growth than virulence specifically.

The remaining mutations affecting genes with well-characterised orthologues correspond to a pair of proteins that potentially function in the same regulatory pathway (Table 2). For one, gene g1354.t1/ODA82845.1, a non-synonymous mutation, L408F, occurred between Swe1 and Swe2. This gene ( $\mathrm{DcPdel}$ ) is predicted to encode a 3' 5'-cAMP phosphodiesterase (PDE). Loss of PDE function would be expected to result in increased cAMP levels. For the second, gene g1885.t1/ODA83372.1, a 20 bp duplication in the Swe1 genome, predicted to render the corresponding protein non-functional, was lost in Swe2. Thus in this case, the mutation would be expected to restore function to the predicted regulatory subunit of a cAMP-dependent protein kinase $(D c C P K A)$. In many fungi, cAMP levels act via cAMP-dependent protein kinases to influence growth, morphology and sporulation (Kim et al., 2011; Wang et al., 2011). Assuming that the mutation of DcPdel is a loss-of-function, in combination with the mutation in DcCPKA, growth and sporulation in Swe2 and Swe3 would be predicted to be more tightly controlled by the ATP/cAMP balance (Fig. 5).

The remaining 3 proteins have poor or non-existent annotation. Genes g7143.t1/ODA77116.1 and g3072.t1/ODA80305.1 that acquired non-synonymous mutations at different steps of culture (Table 2) correspond to hypothetical proteins of unknown function, found in a phylogenetically restricted range of fungi. Still more extreme is the case of fg4743.t1/ODA79924.1. Despite using sensitive search tools (including HHblits (Steinegger et al., 2019) against the UniRef100 database), we were unable to find any plausible homologues in any other species. Indeed, there is no equivalent of fg4743.t1 even in the genomes of the 2 available $D$. coniospora Dan strains. The gene was predicted ab initio with the software tool Augustus (Lebrigand et al., 2016), but has only very marginal RNAseq read support, with 11 and 16 reads in samples from mycelia and spores, respectively, not covering all of the predicted coding sequence and with none of the reads confirming the predicted intron-exon boundaries (Supp. Fig. S6). We were unable to amplify a transcript from cDNA using sequence-specific PCR primers designed on the basis of the existing gene model. Thus 
if such a gene does exist, it is unique to the Swe strains of $D$. coniospora and its sequence gives no clue as to its possible function. Like all the genes described above, its potential role in virulence per se remains to be addressed.

\section{Discussion}

The difference in virulence between Swe1 and its domesticated derivative Swe3 opened a potential path to dissect the molecular basis of pathogenicity in D. coniospora. As mentioned above, at the outset, we had little idea that we would culture D. coniospora for 20 years. Otherwise, we would have made adjustments to our method. We used the wild-type N2 strain of $C$. elegans to propagate $D$. coniospora. In line with recommended practice, the cultures of N2 were replaced from frozen stocks several times a year. Although this was not the specific intention, as a consequence, D. coniospora was grown in a host with an effectively stable genetic background. While this simplifies interpretation of any changes to D. coniospora, had a replicate been included for which N2 was not replaced, but allowed to accumulate mutations, we might have gained insight into host-pathogen co-evolution.

Our in silico analysis was, therefore, necessarily restricted to a genomic comparison of the different $D$. coniospora strains. As a first step, we improved the genome assembly for Swe2, as this served as our reference sequence for gene curation in the other two strains. The refined Swe2 genome is of high quality, with less than 1/1000 undefined bases on average. Given the degree of divergence in long fully-defined regions of the Swe genomes (i.e. 0.5 substitutions per $100 \mathrm{~kb}$ between Swe1 and Swe3), one would expect $<70$ changes in exonic sequence. Thus, we can predict that few if any SNPs and indels affecting protein-coding genes have been overlooked because of the remaining undefined bases. In the context of this study, improving the genome sequences further would require a disproportionate effort for relatively limited potential return.

Unexpectedly, on the basis of standard similarity metrics, the Swe1 and Swe3 sequences were reported to be more similar to each other than to Swe2, which makes little biological sense. This was also the case when the effect of erroneous homopolymer length determination associated with nanopore sequencing was eliminated. This difference is likely to reflect the strategy used to assemble the Swe1 and Swe3 genomes, compared to that for Swe2. Firstly, the average short-read coverage for Swe1 and Swe3 was close to 400X, four times higher than that for Swe2. This should increase the intrinsic sequence accuracy at each position. Perhaps more importantly, the long reads used for assembling the Swe1 and Swe 3 genomes allowed unambiguous positions to be assigned to repeated elements, including transposons. During polishing, short-reads were recruited to the correct sequence with high-fidelity. For the Swe2 genome, without the support of long reads, some repeated elements were mis-positioned, or had an incorrect copy number, leading to genome compression, as described previously (e.g. (Eccles et al., 2018)), and reflected in the slightly smaller (ca. 1\%) total size for the current Swe2 genome. In the absence of correct assembly, some short reads would be mapped to an erroneous genomic region and this recruitment of reads from one or more slightly divergent copies of the same element would lead to inaccuracies in the final sequence. We indeed observed this type of event in our manual inspection of short-read 
mapping to the Swe2 genome. This is likely to be a common artifact when comparing genomes sequenced using different technologies.

The mutations that accumulated in Swe3, compared to Swe1, were far from randomly distributed. Introns and exons represent about $5 \%$ and $40 \%$ of the genome sequence, respectively. Given a divergence rate of about $0.002 \%$ between Swe1 and Swe3, one would expect around 8 and 60 nucleotide changes in introns and exons, respectively. This is very far from our estimates (incorporating the measured true positive rate) of 78 and 20, respectively, presumably a reflection of selection pressure maintaining the integrity of protein-coding genes.

At the DNA level, we found no evidence for incomplete spread of the different alleles that accumulated in Swe2 and then Swe3. In the simplest case of haploid selection, as a very rough estimate, a new allele that confers a $10 \%$ fitness advantage can go from a low to a high frequency in a population in 100 generations, while one associated with a $1 \%$ increase in fitness will take 1000 generations. For this experiment with $D$. coniospora, a generation can be equated to one passage, from the addition of spores to a plate of C. elegans, to the harvesting of new spores, typically 1-2 weeks later. We have no way of knowing exactly when each new allele arose, but given their spread in a relatively small number of generations (estimated to be 25/year on average), excepting any case of hitch-hiking by a neutral allele, each is likely to confer a substantial increase in fitness. Ideally, we would be able to introduce the alleles singly into the Swe1 background (or that of Swe2, as appropriate) to determine their individual contributions to fitness and/or virulence. Our established D. coniospora transformation method (He and Ewbank, 2017) no longer functions and we are not currently able to alter specifically the fungal genome. As an alternative, one can heterologously express candidate virulence factors in C. elegans (Zhang et al., 2021), but this is only appropriate for $D$. coniospora proteins that are predicted to be secreted into the host, which is not the case for any of the candidates identified in the current study.

The most striking molecular change concerned DcCPKA. In Swe1, the gene is predicted to be non-functional, due to a tandem duplication of a short sequence element. This was lost in Swe2, putatively restoring function. Similar effects have been reported following long-term culture of $S$. cerevisiae, including one linked to adenine biosynthesis (ade2-1), wherein mutations reverted a premature stop codon in the parental strain so that the full ADE2 sequence could be translated (Johnson et al., 2021). Rearrangements involving tandem sequence elements like this can arise due to replication slippage and are well-known drivers of genomic change (Hancock, 1996). In the Dan1 and Dan2 genomes, the DcCPKA locus resembles that of Swe2 and is thus predicted to encode a functional protein. Sequence analysis of other environmental isolates of $D$. coniospora will be needed to establish how often $D c C P K A$ function is lost in nature. It would also be extremely interesting to know whether the $D c C P K A$ mutation appeared in our laboratory culture before or after the mutation in DcPde1, but unfortunately we have no cryopreserved samples between Swe1 and Swe2. Since we cannot be certain that the DcPdel mutation in Swe2 represents a loss of function allele, it is also an open question as to whether the 2 mutations, in DcCPKA and DcPdel, are compensatory or mutually reinforce an effect on PKA signaling. Our current model is that the Swe2 DcCPKA allele encodes a functional regulatory protein, subject to control by cAMP levels, and that with decreased DcPdelp activity, the PKA pathway is more repressed in 
Swe2 than Swe1 for given levels of ATP and adenylate cyclase activity. This model could be tested by site-specific mutation of the Swe1 genome, but, unfortunately, as explained above, this is currently not possible. Indeed, this is an important barrier to making definitive causative links between any of the observed mutations and the observed alteration of virulence.

Another potential limitation of our study reflects the use of Swe2 gene set as our reference. While we found no more paralogues for Dan2 genes in the Swe1 genome than in the Swe2 genome, if there are genes with mutations substantially altering their predicted coding sequence (e.g. introduction of a premature stop codon) in Swe2, they would be missing from the gene set and therefore not included in our analysis. Nevertheless, in common with DcCPKA and DcPde1, several of the mutations that were identified between Swel and Swe 3 are likely to play general roles in fungal growth. Compared to the natural environment, laboratory culture conditions are relatively constant and it may be advantageous for $D$. coniospora to lose regulatory pathways that are not needed, as has been seen in other evolution experiments (reviewed in (Kvitek and Sherlock, 2013; McDonald, 2019). Indeed, in one replicated study, a majority of mutations were found in three major signaling networks that regulate growth control, including the Ras/cAMP/PKA pathway that in $D$. coniospora involves $D c C P K A$ and DcPdel. Although such mutations are predicted to be beneficial in a stable environment, they generally come at the cost of eliminating the metabolic plasticity needed when nutrient supplies change. We assume that this type of mutation will impact pathogenesis through a general effect on growth. It remains an open question whether any of the other mutations we identified in 3 unannotated predicted hypothetical proteins might impact virulence per se. As they are not predicted to be secreted, they are unlikely to be direct effectors of fungal virulence, but could conceivably be involved in the regulation of virulence factor gene expression. In the absence of tools for site-directed mutagenesis, determining their function remains a challenge for the future.

\section{Data Availability}

All relevant data can be accessed either at the EBI/NCBI/DDBJ via BioProject PRJNA269584, or on our institutional server at http://www.ciml.univ-mrs.fr/applications/DC/Genome.htm.

\section{Acknowledgements}

We thank Marie-Anne Félix for insightful comments, Philippe Fort for helpful discussion concerning Ras GAP function and phylogeny, and the CIML imaging (ImagImm) and bioinformatics platforms.

\section{Funding}

This work was supported by institutional grants from the Institut National de la Santé et de la Recherche Médicale, Centre National de la Recherche Scientifique and Aix-Marseille 
University to the CIML, and the Agence Nationale de la Recherche program grant (ANR-16-CE15-0001-01), and "Investissements d'Avenir" ANR-11-LABX-0054 (Labex INFORM), ANR-16-CONV-0001, and ANR-11-IDEX-0001-02, and from the Excellence Initiative of Aix-Marseille University - A*MIDEX

\section{References}

Altschul, S.F., Madden, T.L., Schaffer, A.A., Zhang, J., Zhang, Z., Miller, W., and Lipman, D.J. (1997). Gapped BLAST and PSI-BLAST: a new generation of protein database search programs. Nucleic Acids Res. 25, 3389-3402.

Andersson, K.M., Kumar, D., Bentzer, J., Friman, E., Ahren, D., and Tunlid, A. (2014). Interspecific and host-related gene expression patterns in nematode-trapping fungi. BMC Genomics 15, 968.

van den Boogert, P.H.J.F., Dijksterhuis, J., Velvis, H., and Veenhuis, M. (1992). Adhesive knob formation by conidia of the nematophagous fungus Drechmeria coniospora. Antonie Van Leeuwenhoek 61, 221-229.

Brunk, M., Sputh, S., Doose, S., van de Linde, S., and Terpitz, U. (2018). HyphaTracker: An Image J toolbox for time-resolved analysis of spore germination in filamentous fungi. Sci. Rep. 8, 605 .

Chung, D., Barker, B.M., Carey, C.C., Merriman, B., Werner, E.R., Lechner, B.E., Dhingra, S., Cheng, C., Xu, W., Blosser, S.J., et al. (2014). ChIP-seq and In Vivo Transcriptome Analyses of the Aspergillus fumigatus SREBP SrbA Reveals a New Regulator of the Fungal Hypoxia Response and Virulence. PLoS Pathog. 10, e1004487.

Courtine, D., Provaznik, J., Reboul, J., Blanc, G., Benes, V., and Ewbank, J.J. (2020). Long-read only assembly of Drechmeria coniospora genomes reveals widespread chromosome plasticity and illustrates the limitations of current nanopore methods. GigaScience 9, giaa099.

Darling, A.C.E., Mau, B., Blattner, F.R., and Perna, N.T. (2004). Mauve: multiple alignment of conserved genomic sequence with rearrangements. Genome Res. 14, 1394-1403.

Dierking, K., Polanowska, J., Omi, S., Engelmann, I., Gut, M., Lembo, F., Ewbank, J.J., and Pujol, N. (2011). Unusual regulation of a STAT protein by an SLC6 family transporter in $C$. elegans epidermal innate immunity. Cell Host Microbe 9, 425-435.

Eccles, D., Chandler, J., Camberis, M., Henrissat, B., Koren, S., Le Gros, G., and Ewbank, J.J. (2018). De novo assembly of the complex genome of Nippostrongylus brasiliensis using MinION long reads. BMC Biol. 16, 6.

Ekroth, A.K.E., Gerth, M., Stevens, E.J., Ford, S.A., and King, K.C. (2021). Host genotype and genetic diversity shape the evolution of a novel bacterial infection. ISME J. 15, 2146-2157. 
Gernandt, D.S., and Stone, J.K. (1999). Phylogenetic Analysis of Nuclear Ribosomal DNA Places the Nematode Parasite, Drechmeria coniospora, in Clavicipitaceae. Mycologia 91, 993-1000.

Good, B.H., McDonald, M.J., Barrick, J.E., Lenski, R.E., and Desai, M.M. (2017). The dynamics of molecular evolution over 60,000 generations. Nature 551, 45-50.

Hancock, J.M. (1996). Simple sequences and the expanding genome. BioEssays News Rev. Mol. Cell. Dev. Biol. 18, 421-425.

He, L.D., and Ewbank, J.J. (2017). Polyethylene Glycol-mediated Transformation of Drechmeria coniospora. Bio-Protoc. 7, e2157.

Heitman, J., Kronstad, J.W., Taylor, J.W., and Casselton, L.A. (2007). Sex in fungi: molecular determination and evolutionary implications. Wiley.

Hughes, A.L., Todd, B.L., and Espenshade, P.J. (2005). SREBP Pathway Responds to Sterols and Functions as an Oxygen Sensor in Fission Yeast. Cell 120, 831-842.

Iqbal, M., Dubey, M., Gudmundsson, M., Viketoft, M., Jensen, D.F., and Karlsson, M. (2018). Comparative evolutionary histories of fungal proteases reveal gene gains in the mycoparasitic and nematode-parasitic fungus Clonostachys rosea. BMC Evol. Biol. 18, 171.

Isono, E., Saeki, Y., Yokosawa, H., and Toh-e, A. (2004). Rpn7 Is required for the structural integrity of the $26 \mathrm{~S}$ proteasome of Saccharomyces cerevisiae. J. Biol. Chem. 279, $27168-27176$.

Jansson, H.B., and Friman, E. (1999). Infection-related surface proteins on conidia of the nematophagous fungus Drechmeria coniospora. Mycol. Res. 103, 249-256.

Ji, X., Yu, Z., Yang, J., Xu, J., Zhang, Y., Liu, S., Zou, C., Li, J., Liang, L., and Zhang, K.-Q. (2020). Expansion of Adhesion Genes Drives Pathogenic Adaptation of Nematode-Trapping Fungi. IScience 23, 101057.

Johnson, M.S., Gopalakrishnan, S., Goyal, J., Dillingham, M.E., Bakerlee, C.W., Humphrey, P.T., Jagdish, T., Jerison, E.R., Kosheleva, K., Lawrence, K.R., et al. (2021). Phenotypic and molecular evolution across 10,000 generations in laboratory budding yeast populations. ELife 10, e63910.

Kim, H.-S., Park, S.-Y., Lee, S., Adams, E.L., Czymmek, K., and Kang, S. (2011). Loss of cAMP-Dependent Protein Kinase A Affects Multiple Traits Important for Root Pathogenesis by Fusarium oxysporum. Mol. Plant. Microbe Interact. 24, 719-732.

Kvitek, D.J., and Sherlock, G. (2013). Whole genome, whole population sequencing reveals that loss of signaling networks is the major adaptive strategy in a constant environment. PLoS Genet. 9, e1003972.

Labed, S.A, Omi, S., Gut, M., Ewbank, J.J., and Pujol, N. (2012). The Pseudokinase NIPI-4 Is a Novel Regulator of Antimicrobial Peptide Gene Expression. PLoS ONE 7, e33887.

Lebrigand, K., He, L.D., Thakur, N., Arguel, M.-J., Polanowska, J., Henrissat, B., Record, E., 
Magdelenat, G., Barbe, V., Raffaele, S., et al. (2016). Comparative Genomic Analysis of Drechmeria coniospora Reveals Core and Specific Genetic Requirements for Fungal Endoparasitism of Nematodes. PLoS Genet. 12, e1006017.

Lee, H., Bien, C.M., Hughes, A.L., Espenshade, P.J., Kwon-Chung, K.J., and Chang, Y.C. (2007). Cobalt chloride, a hypoxia-mimicking agent, targets sterol synthesis in the pathogenic fungus Cryptococcus neoformans. Mol. Microbiol. 65, 1018-1033.

Lee, K.Z., Kniazeva, M., Han, M., Pujol, N., and Ewbank, J.J. (2010). The fatty acid synthase fasn-1 acts upstream of WNK and Ste20/GCK-VI kinases to modulate antimicrobial peptide expression in C. elegans epidermis. Virulence 1, 113-122.

Lee, S.H., Omi, S., Thakur, N., Taffoni, C., Belougne, J., Engelmann, I., Ewbank, J.J., and Pujol, N. (2018). Modulatory upregulation of an insulin peptide gene by different pathogens in C. elegans. Virulence 9, 648-658.

Lenski, R.E. (2017). Experimental evolution and the dynamics of adaptation and genome evolution in microbial populations. ISME J. 11, 2181-2194.

Li, H. (2018a). Minimap2: pairwise alignment for nucleotide sequences. Bioinformatics 34, 3094-3100.

Li, H. (2018b). On the definition of sequence identity, https://lh3.github.io/2018/11/25/on-the-definition-of-sequence-identity.

Li, Y., Steenwyk, J.L., Chang, Y., Wang, Y., James, T.Y., Stajich, J.E., Spatafora, J.W., Groenewald, M., Dunn, C.W., Hittinger, C.T., et al. (2021). A genome-scale phylogeny of the kingdom Fungi. Curr. Biol. 31, 1653-1665.e5.

Lin, R., Qin, F., Shen, B., Shi, Q., Liu, C., Zhang, X., Jiao, Y., Lu, J., Gao, Y., Suarez-Fernandez, M., et al. (2018). Genome and secretome analysis of Pochonia chlamydosporia provide new insight into egg-parasitic mechanisms. Sci. Rep. 8, 1123.

Liu, Z., Jian, Y., Chen, Y., Kistler, H.C., He, P., Ma, Z., and Yin, Y. (2019). A phosphorylated transcription factor regulates sterol biosynthesis in Fusarium graminearum. Nat. Commun. $10,1228$.

Marçais, G., Delcher, A.L., Phillippy, A.M., Coston, R., Salzberg, S.L., and Zimin, A. (2018). MUMmer4: A fast and versatile genome alignment system. PLoS Comput. Biol. 14, e1005944.

Masri, L., Branca, A., Sheppard, A.E., Papkou, A., Laehnemann, D., Guenther, P.S., Prahl, S., Saebelfeld, M., Hollensteiner, J., Liesegang, H., et al. (2015). Host-Pathogen Coevolution: The Selective Advantage of Bacillus thuringiensis Virulence and Its Cry Toxin Genes. PLoS Biol. 13, e1002169.

McDonald, M.J. (2019). Microbial Experimental Evolution - a proving ground for evolutionary theory and a tool for discovery. EMBO Rep. 20, e46992.

Meerupati, T., Andersson, K.M., Friman, E., Kumar, D., Tunlid, A., and Ahren, D. (2013). 
Genomic mechanisms accounting for the adaptation to parasitism in nematode-trapping fungi. PLoS Genet. 9, e1003909.

Morran, L.T., Schmidt, O.G., Gelarden, I.A., Parrish, R.C., and Lively, C.M. (2011). Running with the Red Queen: host-parasite coevolution selects for biparental sex. Science 333, 216-218.

Müller, M.P., and Goody, R.S. (2018). Molecular control of Rab activity by GEFs, GAPs and GDI. Small GTPases 9, 5-21.

Ni, L., and Snyder, M. (2001). A Genomic Study of the Bipolar Bud Site Selection Pattern in Saccharomyces cerevisiae. Mol. Biol. Cell 12, 2147-2170.

Olm, M.R., Brown, C.T., Brooks, B., and Banfield, J.F. (2017). dRep: a tool for fast and accurate genomic comparisons that enables improved genome recovery from metagenomes through de-replication. ISME J. 11, 2864-2868.

Paulino, D., Warren, R.L., Vandervalk, B.P., Raymond, A., Jackman, S.D., and Birol, I. (2015). Sealer: a scalable gap-closing application for finishing draft genomes. BMC Bioinformatics 16, 230.

Peng, Y., Leung, H.C.M., Yiu, S.M., and Chin, F.Y.L. (2012). IDBA-UD: a de novo assembler for single-cell and metagenomic sequencing data with highly uneven depth. Bioinformatics 28, 1420-1428.

Powell, J.R., and Ausubel, F.M. (2008). Models of Caenorhabditis elegans Infection by Bacterial and Fungal Pathogens. Innate Immunity, p. 403-427.

Pritchard, L., Glover, R.H., Humphris, S., Elphinstone, J.G., and Toth, I.K. (2015). Genomics and taxonomy in diagnostics for food security: soft-rotting enterobacterial plant pathogens. Anal. Methods 8, 12-24.

Pujol, N., Cypowyj, S., Ziegler, K., Millet, A., Astrain, A., Goncharov, A., Jin, Y., Chisholm, A.D., and Ewbank, J.J. (2008). Distinct innate immune responses to infection and wounding in the C. elegans epidermis. Curr Biol 18, 481-489.

Saikawa, M. (1982). An electron microscope study of Meria coniospora, an endozoic nematophagous Hyphomycete. Can. J. Bot. 60, 2019-2023.

Schindelin, J., Arganda-Carreras, I., Frise, E., Kaynig, V., Longair, M., Pietzsch, T., Preibisch, S., Rueden, C., Saalfeld, S., Schmid, B., et al. (2012). Fiji: an open-source platform for biological-image analysis. Nat. Methods 9, 676-682.

Schulte, R.D., Hasert, B., Makus, C., Michiels, N.K., and Schulenburg, H. (2012). Increased responsiveness in feeding behaviour of Caenorhabditis elegans after experimental coevolution with its microparasite Bacillus thuringiensis. Biol. Lett. 8, 234-236.

Slater, G.S.C., and Birney, E. (2005). Automated generation of heuristics for biological sequence comparison. BMC Bioinformatics 6, 31 . 
van Slegtenhorst, M., Carr, E., Stoyanova, R., Kruger, W.D., and Henske, E.P. (2004). Tsc1+ and tsc2+ Regulate Arginine Uptake and Metabolism in Schizosaccharomyces pombe. J. Biol. Chem. 279, 12706-12713.

Steinegger, M., Meier, M., Mirdita, M., Vöhringer, H., Haunsberger, S.J., and Söding, J. (2019). HH-suite3 for fast remote homology detection and deep protein annotation. BMC Bioinformatics 20, 473.

Stiernagle, T. (2006). Maintenance of $C$. elegans. WormBook : the online review of $C$. elegans biology, 1-11.

Wang, C., Zhang, S., Hou, R., Zhao, Z., Zheng, Q., Xu, Q., Zheng, D., Wang, G., Liu, H., Gao, X., et al. (2011). Functional Analysis of the Kinome of the Wheat Scab Fungus Fusarium graminearum. PLoS Pathog. 7, e1002460.

Wang, R., Dong, L., He, R., Wang, Q., Chen, Y., Qu, L., and Zhang, Y.-A. (2018). Comparative genomic analyses reveal the features for adaptation to nematodes in fungi. DNA Res. 25, 245-256.

White, P.S., Choi, A., Pandey, R., Menezes, A., Penley, M., Gibson, A.K., de Roode, J., and Morran, L. (2020). Host heterogeneity mitigates virulence evolution. Biol. Lett. 16, 20190744.

White, P.S., Arslan, D., Kim, D., Penley, M., and Morran, L. (2021). Host genetic drift and adaptation in the evolution and maintenance of parasite resistance. J. Evol. Biol. 34, 845-851. Wintersinger, J.A., and Wasmuth, J.D. (2015). Kablammo: an interactive, web-based BLAST results visualizer. Bioinformatics 31, 1305-1306.

Wyatt, T.T., Wösten, H.A.B., and Dijksterhuis, J. (2013). Fungal spores for dispersion in space and time. Adv. Appl. Microbiol. 85, 43-91.

Xie, J., Li, S., Mo, C., Xiao, X., Peng, D., Wang, G., and Xiao, Y. (2016). Genome and Transcriptome Sequences Reveal the Specific Parasitism of the Nematophagous Purpureocillium lilacinum 36-1. Front. Microbiol. 7, 1084.

Zhang, L., Zhou, Z., Guo, Q., Fokkens, L., Miskei, M., Pócsi, I., Zhang, W., Chen, M., Wang, L., Sun, Y., et al. (2016). Insights into Adaptations to a Near-Obligate Nematode Endoparasitic Lifestyle from the Finished Genome of Drechmeria coniospora. Sci. Rep. 6, 23122.

Zhang, X., Harding, B.W., Aggad, D., Courtine, D., Chen, J.-X., Pujol, N., and Ewbank, J.J. (2021). Antagonistic fungal enterotoxins intersect at multiple levels with host innate immune defences. PLoS Genet. 17, e1009600.

Zugasti, O., Thakur, N., Belougne, J., Squiban, B., Kurz, C.L., Soulé, J., Omi, S., Tichit, L., Pujol, N., and Ewbank, J.J. (2016). A quantitative genome-wide RNAi screen in C. elegans for antifungal innate immunity genes. BMC Biol. 14, 35 . 
bioRxiv preprint doi: https://doi.org/10.1101/2021.09.01.457749; this version posted September 3, 2021. The copyright holder for this

preprint (which was not certified by peer review) is the author/funder, who has granted bioRxiv a license to display the preprint in perpetuity. It is made available under aCC-BY-NC-ND 4.0 International license.
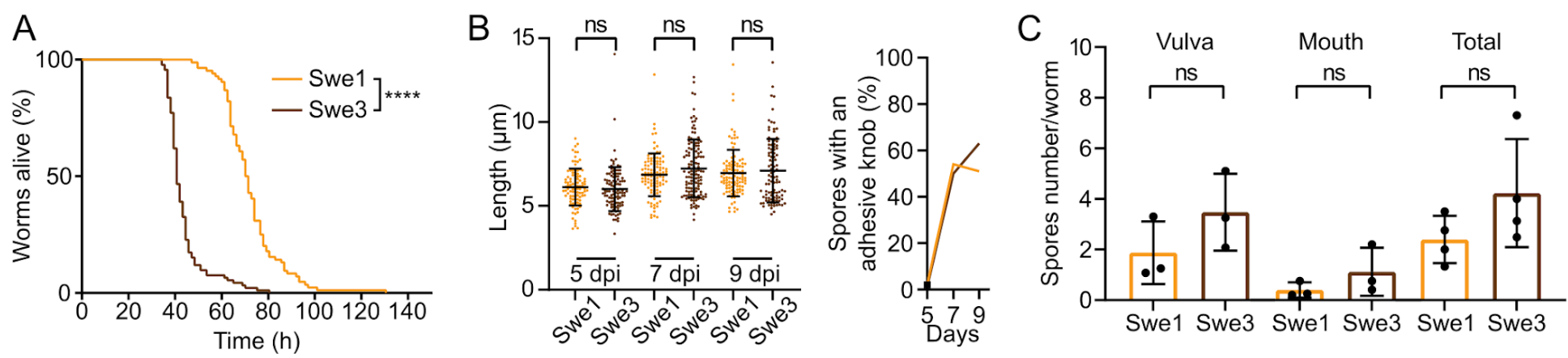

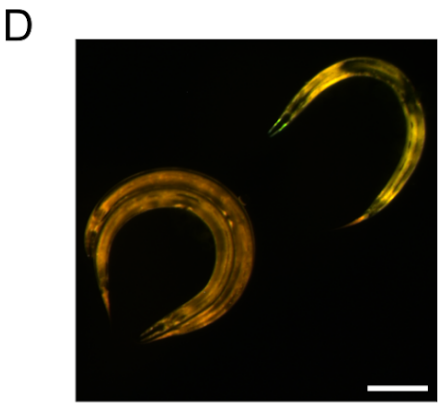

$\mathrm{NI}$

$16 \mathrm{~h}$

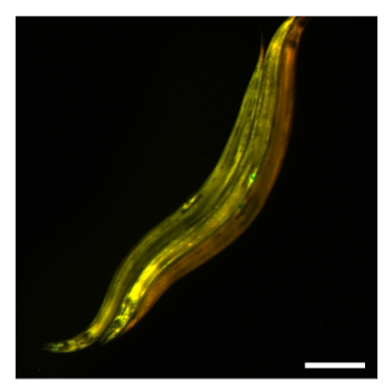

Swe1

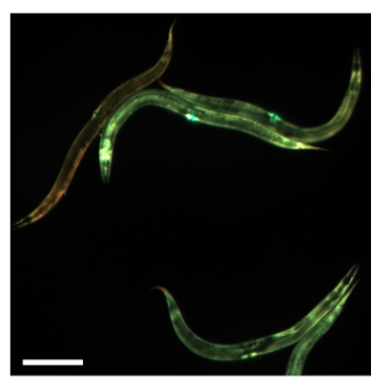

Swe3

$16 \mathrm{hpi}$
E

Swe1

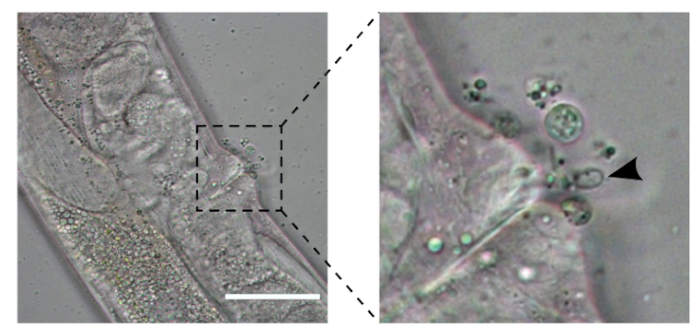

Swe3

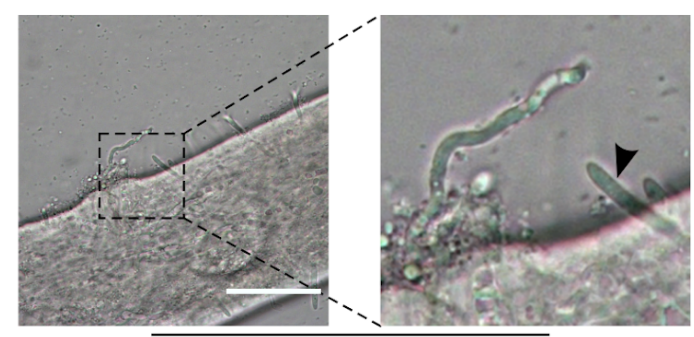

$48 \mathrm{hpi}$

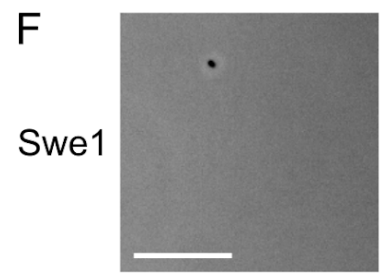

Swe3

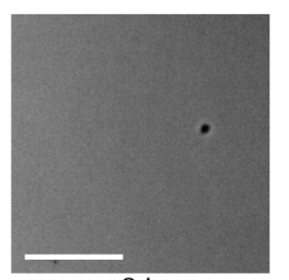

$2 \mathrm{~h}$
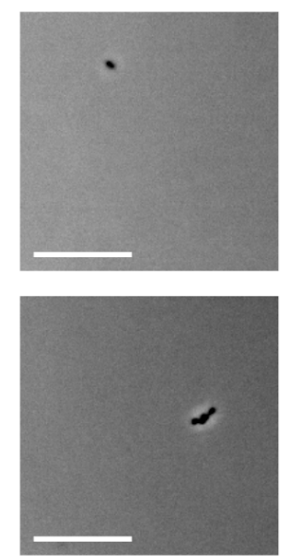

$22 \mathrm{~h}$
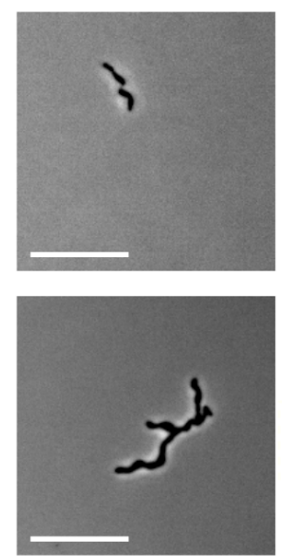

$44 \mathrm{~h}$
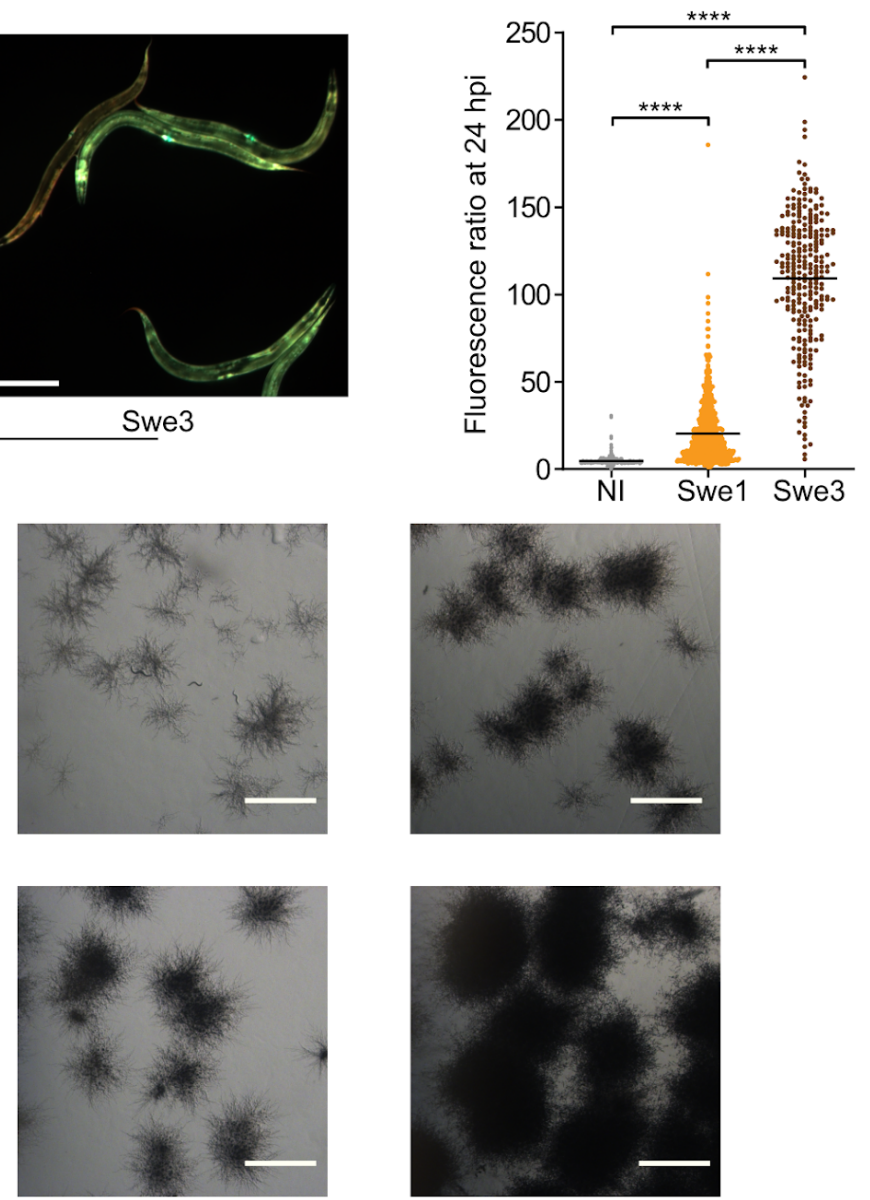

$96 \mathrm{hpi}$
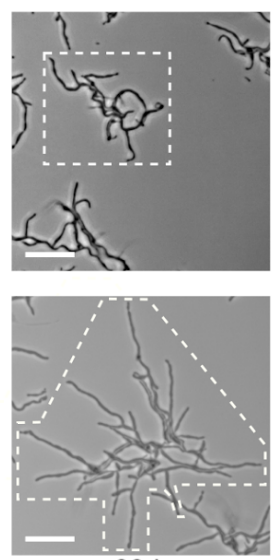

$69 \mathrm{~h}$

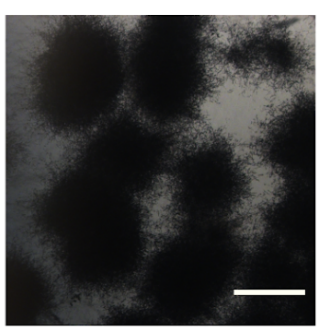

$144 \mathrm{hpi}$
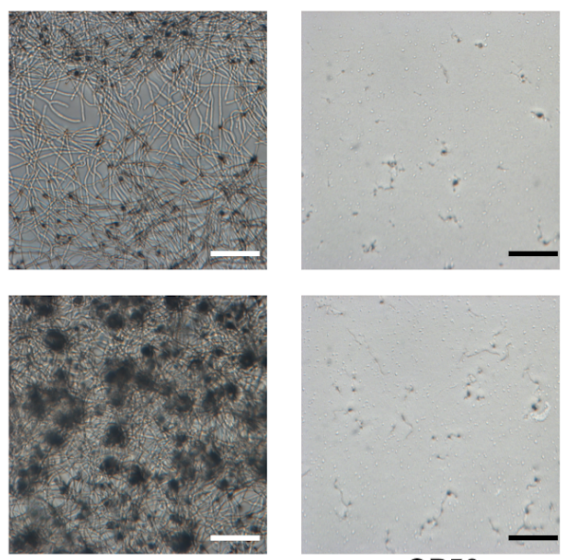

$-96 \mathrm{~h}$ 
Figure 1: Phenotypic differences between Swe1 and Swe3. (A) Survival of C. elegans worms (strain IG463) following infection at $25^{\circ} \mathrm{C}$ with $1 \times 10^{9}$ spores of Swe1 or Swe3; $\mathrm{n}=100$ for each strain, $* * * * \mathrm{p}<0.0001$, one-sided log rank test. The results are representative of three independent trials. (B) Comparison of the size (left) and prevalence of adhesive buds (right), for spores from Swe1 and Swe3. A minimum of 100 spores were scored at each time point. (C) The number of spores at the mouth and vulval regions of C. elegans was counted after 15 $\mathrm{h}$ of infection with $1 \times 10^{9}$ spores of Swe1 or Swe3. Each dot represents the mean of an experiment with at least 10 worms; ns = not significant, two tailed unpaired t-test. (D) Left hand panels: Representative fluorescence images of age-matched IG463 worms uninfected (NI) or infected for $16 \mathrm{~h}$ (16 hpi) with Swe1 or Swe3. The worm strain carries the integrated transgene frIs 7 that includes nlp-29p::GFP and col-12p::dsRed transgenes; red and green fluorescence is visualized simultaneously; scale bar: $200 \mu \mathrm{m}$. Quantification of the green/red fluorescence ratio (in arbitrary units) of IG463 worms at 24 hpi, compared to aged-matched non-infected (NI) worms; $\mathrm{n}>250$ worms for each, **** $\mathrm{p}<0.0001$, unpaired t-test. (E) Representative images of Swe 1 or Swe3 infected worms at 48, 96 and 144 hpi. The $2^{\text {nd }}$ panels from the left are a higher magnification of the indicated vulval regions. The arrowhead highlights Swel spores attached to the vulva (top), and hyphae growing out from the Swe3-infected worm (bottom); scale bar: $50 \mu \mathrm{m}$. The righthand panels show hyphae growing from dead worms; scale bar: $1 \mathrm{~mm}$. (F) Spores of Swe1 or Swe3 (harvested 6 dpi) were seeded on NGM plates, incubated at $25^{\circ} \mathrm{C}$ without worms and images taken at the indicated times. The extent of hyphal growth from a single spore is delimited by dotted lines in the images at $69 \mathrm{~h}$. The two right-hand columns illustrate the degree of spore germination with or without OP50 after 96 h; scale bar: $100 \mu \mathrm{m}$. 


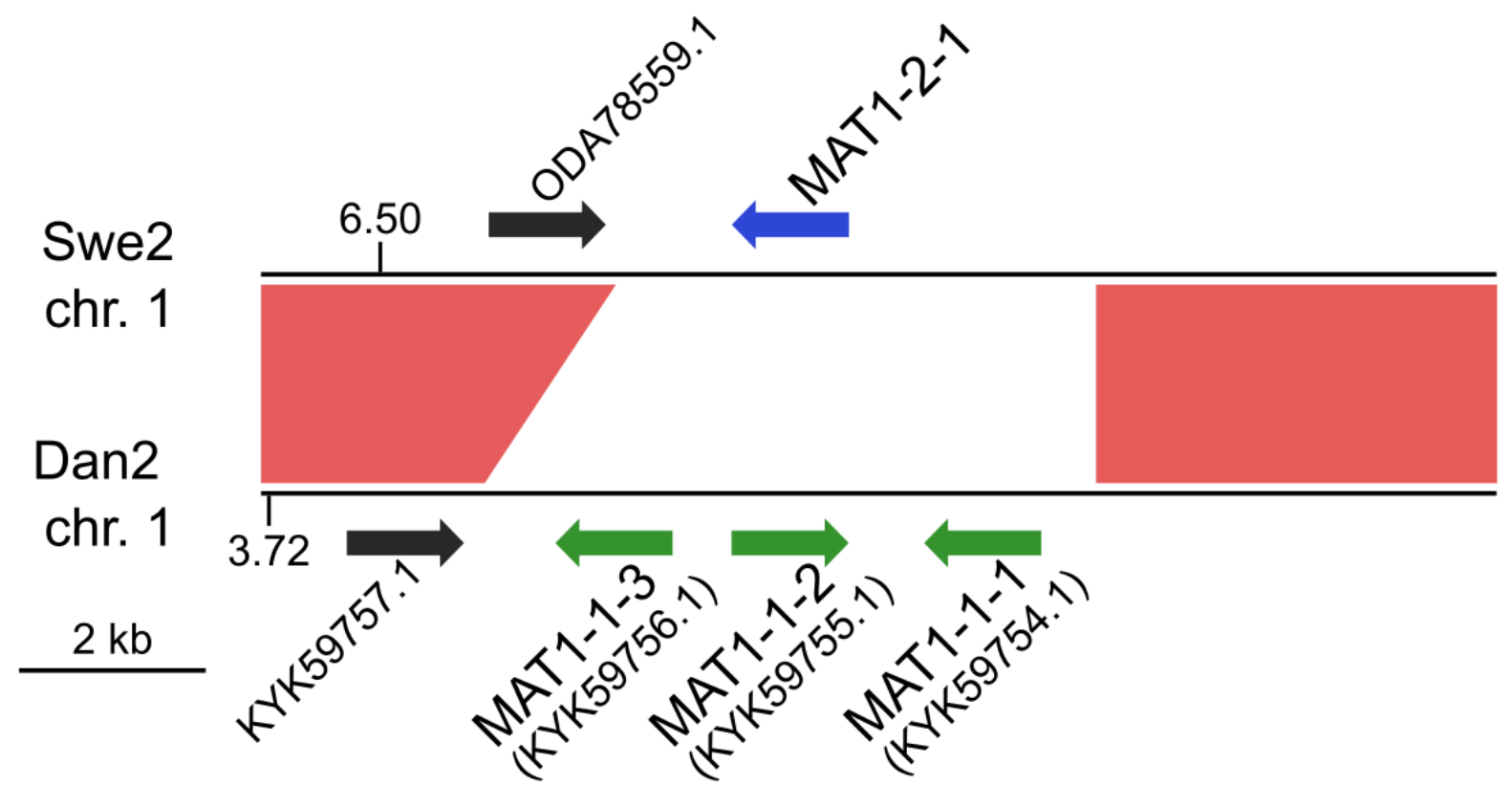

Figure 2: MAT loci in D. coniospora. The Swe2 region syntenic to the Dan2 MAT locus is shown. The previously annotated Dan2 MAT genes are indicated with green arrows, labeled with their idiomorph identifiers. The newly identified Swe2 MAT1-2-1 gene is shown in blue. The red shapes highlight the extent of the sequence synteny, and the black arrows represent a pair of neighbouring orthologous genes.

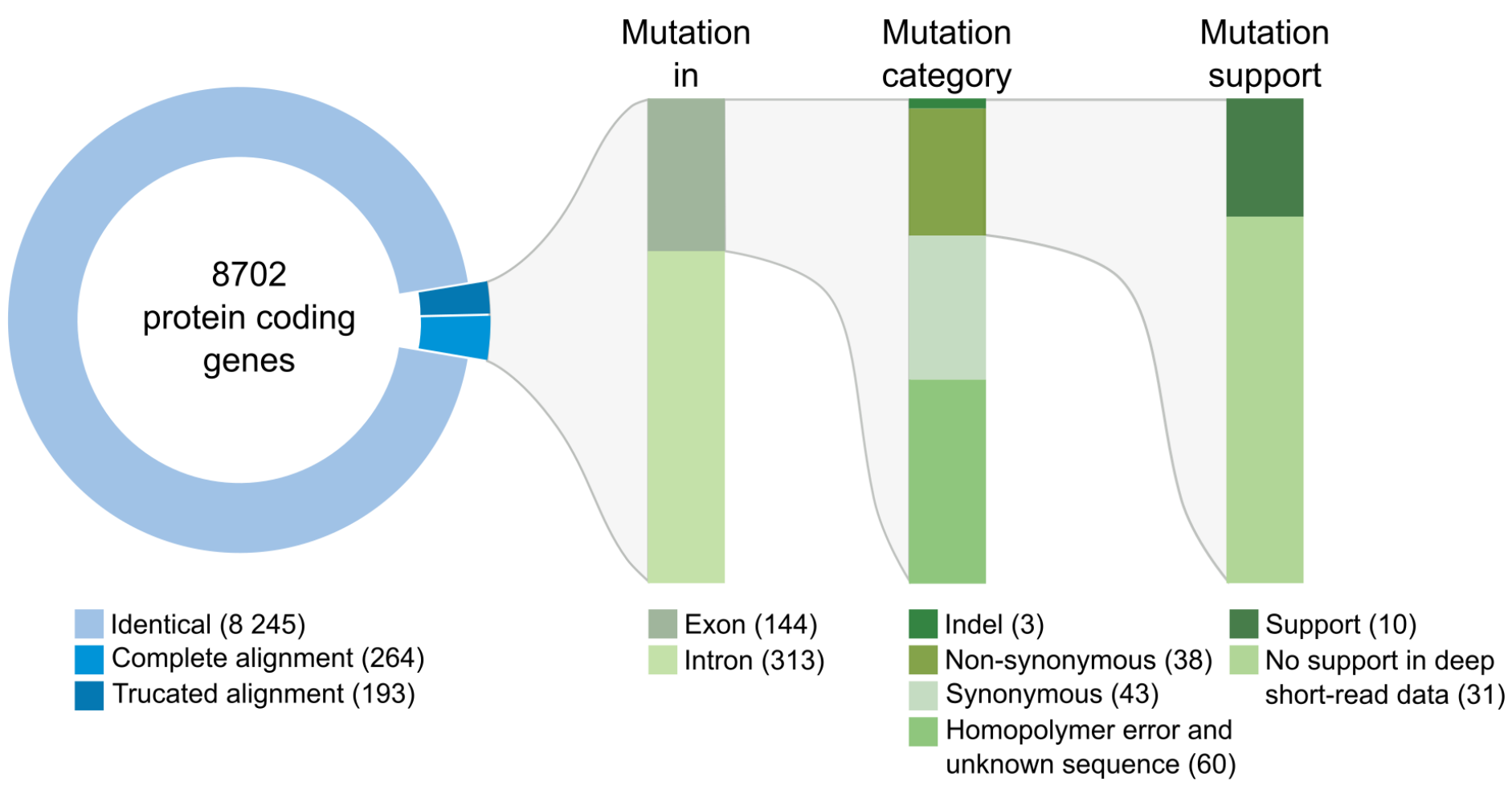

Figure 3: Classification of mutations identified between the genomes of the Swe strains. The overview includes the number of genes and mutations identified at each step of the workflow (see Methods for details). Mutations identified in introns were individually examined; none affected splice donor or acceptor sites. 

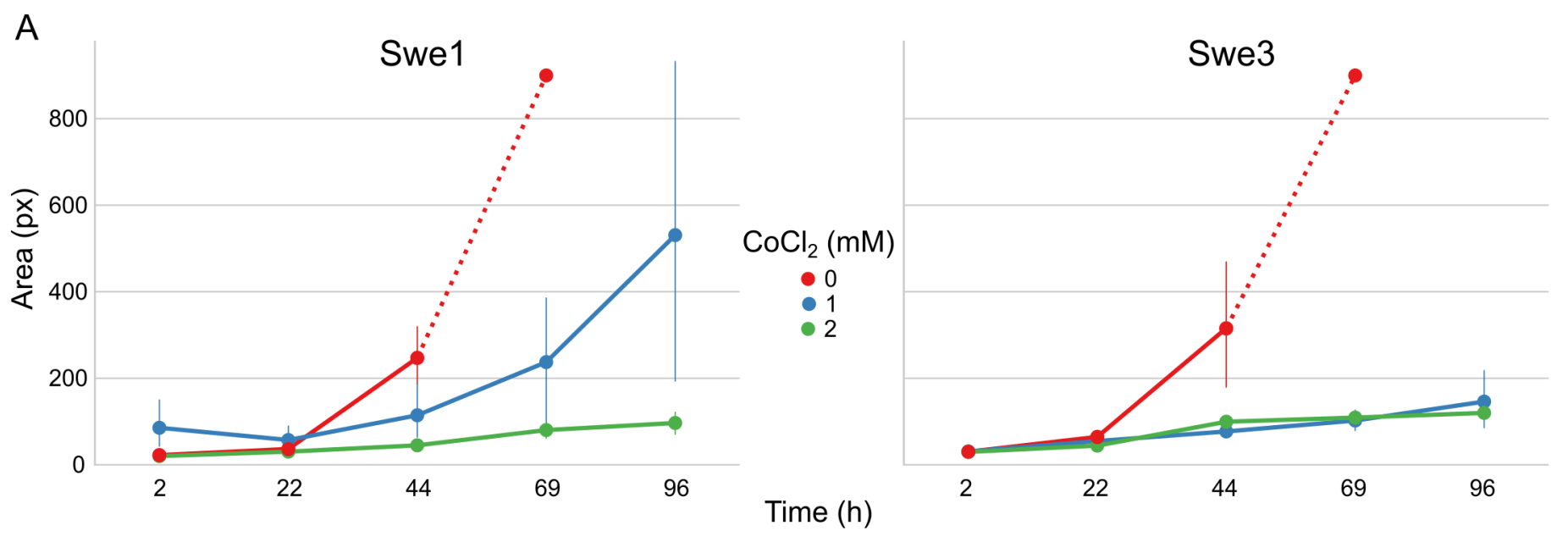

B

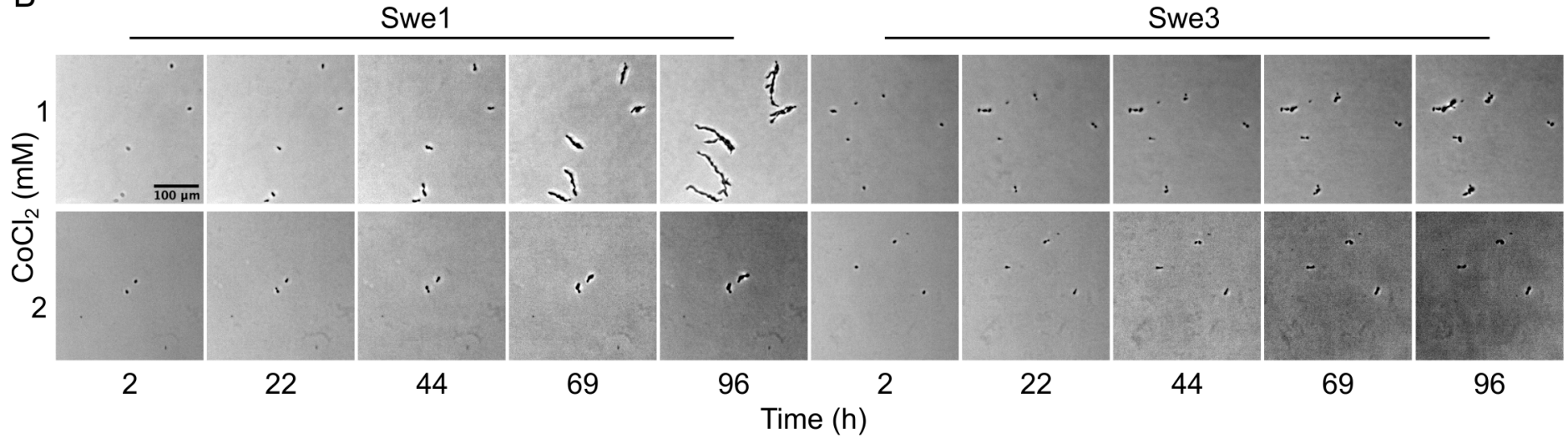

Figure 4: Comparison of the growth of Swe1 and Swe3 in hypoxia-like conditions. (A) Quantification of growth rates for Swe1 and Swe 3 on standard NGM plates $(0 \mathrm{mM})$, or plates supplemented with $\mathrm{CoCl}_{2}$ to a final concentration of 1 or $2 \mathrm{mM}$. As illustrated in Figure 1F, measurement beyond $44 \mathrm{~h}$ of Swe1 and Swe 3 growth in the absence of $\mathrm{CoCl}_{2}$ is confounded by the overgrowth of mycelia derived from separate spores. The average size and $95 \%$ confidence interval for 8 - 35 individual spores per condition, followed at each time point, are shown. (B) Representative images of spores of Swe1 and Swe3 growing in the presence of 1 or $2 \mathrm{mM} \mathrm{CoCl}_{2}$. A direct comparison can be made with Figure $1 \mathrm{~F}$, as the experiments were conducted in parallel. 


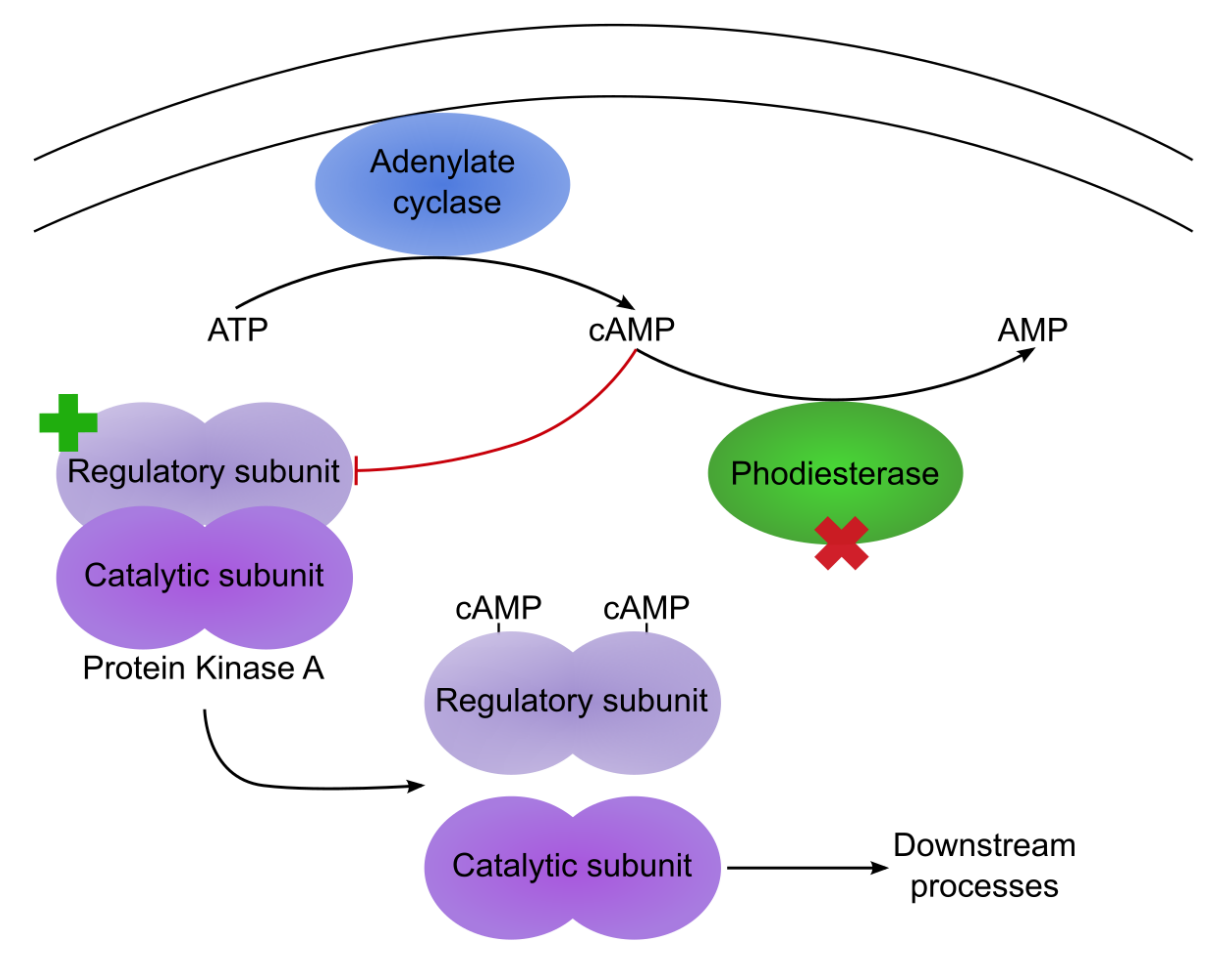

Figure 5: Two mutations potentially affect the same pathway. Simplified diagram illustrating the regulation of protein kinase A (PKA) by cAMP. Under low cAMP condition, the PKA regulatory and catalytic subunits dimerize, leading to an inactive PKA. In Swe1, as the regulatory subunit is constitutively inactive, PKA would be predicted to be permanently active. In Swe2, the inactivating mutation of the regulatory subunit is reverted to wild-type (as indicated by the green cross), so PKA would again come under the control of cAMP levels. Its activity is also regulated by a cAMP phosphodiesterase (PDE), as this converts cAMP to AMP. The PDE bears a non-synonymous mutation in Swe2 (red cross). Assuming that this corresponds to a loss of function, the two mutations would act synergistically, as cAMP would accumulate, thereby accentuating the suppression of repression of PKA activity. Thus PKA would be predicted to be more active in Swe2 (and Swe3) than in Swe1 under the same culture conditions. 
bioRxiv preprint doi: https://doi.org/10.1101/2021.09.01.457749; this version posted September 3, 2021. The copyright holder for this

preprint (which was not certified by peer review) is the author/funder, who has granted bioRxiv a license to display the preprint in perpetuity. It is made available under aCC-BY-NC-ND 4.0 International license.

Table 1: Differences between the Swe genomes

Frequency of differences (per Mb)

\begin{tabular}{|cccccc} 
Query & Subject & $\begin{array}{c}\text { With homopolymers } \\
\text { gap-excluded } \\
\text { (Ns removed) }\end{array}$ & gap-compressed & $\begin{array}{c}\text { Without homopolymers } \\
\text { (Ns removed) }\end{array}$ & gap-compressed \\
\hline Swe1 & Swe2 & 34 & 550 & 32 & 425 \\
\hline Swe2 & Swe1 & 40 & 512 & 39 & 387 \\
\hline Swe1 & Swe3 & 15 & 83 & 6 & 1 \\
\hline Swe3 & Swe1 & 11 & 86 & 5 & 1 \\
Swe2 & Swe3 & 45 & 512 & 30 & 400 \\
Swe3 & Swe2 & 47 & 550 & 32 & 412 \\
\hline
\end{tabular}


bioRxiv preprint doi: https://doi.org/10.1101/2021.09.01.457749; this version posted September 3, 2021. The copyright holder for this

preprint (which was not certified by peer review) is the author/funder, who has granted bioRxiv a license to display the preprint in perpetuity. It is made available under aCC-BY-NC-ND 4.0 International license.

Table 2: Summary of non-synonymous mutations

\begin{tabular}{|c|c|c|c|c|c|c|c|}
\hline Gene & Protein ID & Location & $\begin{array}{l}\text { Mutation } \\
\text { appearance }\end{array}$ & Mutation & Protein change & $\begin{array}{l}\text { Protein } \\
\text { length }\end{array}$ & Function \\
\hline fg4743.t1 & ODA79924.1 & $\begin{array}{c}\operatorname{chr} 3 \\
6981485 . .6983062\end{array}$ & Swe1 > Swe2 & G1421C & $\operatorname{Ser}(A G C) 347 \operatorname{Thr}(A C C)$ & 398 & unknown function \\
\hline g1354.t1 & ODA82845.1 & $\begin{array}{c}\text { chr } 2 \\
5101688 . .5104354\end{array}$ & Swe1 > Swe2 & C1377T & Leu(CTT) 408 Phe(TTT) & 813 & cAMP phosphodiesterase \\
\hline g3072.t1 & ODA80305.1 & $\begin{array}{c}\text { chr } 1 \\
4336085 . .4336645\end{array}$ & Swe1 > Swe2 & C490A & GIn(CAG) 164 Lys(AAG) & 186 & unknown function \\
\hline g8020.t1 & ODA75964.1 & $\begin{array}{c}\text { chr } 3 \\
10903448 . .10905186\end{array}$ & Swe1 > Swe2 & A1230G & Asn(AAC) 319 Asp(GAC) & 487 & Ras family \\
\hline g1885.t1 & ODA83372.1 & $\begin{array}{c}\text { chr } 2 \\
3206066.3207273\end{array}$ & Swe1 > Swe2 & $\begin{array}{l}\text { del } 196 \text { AGCTACCC } \\
\text { GGCTCAGTACAA }\end{array}$ & Premature stop & 378 & $\begin{array}{l}\text { cAMP dependent protein } \\
\text { kinase }\end{array}$ \\
\hline g7143.t1 & ODA77116.1 & $\begin{array}{c}\operatorname{chr} 2 \\
10184692 . .10185816\end{array}$ & Swe2 > Swe3 & C323T & Ser(TCA) 74 Leu(TTA) & 340 & unknown function \\
\hline g7471.t1 & ODA76724.1 & $\begin{array}{c}\text { chr } 3 \\
1598585 . .1601730\end{array}$ & Swe2 > Swe3 & G1486A & $\begin{array}{c}\operatorname{Trp}(\mathrm{TGG}) 431 \mathrm{STOP} \\
\text { (TGA) }\end{array}$ & 964 & Hamartin \\
\hline g7915.t1 & ODA75859.1 & $\begin{array}{c}\text { chr } 3 \\
10553741 . .10555370\end{array}$ & Swe2 > Swe3 & G397T & Asp(GAC) 133 Tyr(TAC) & 490 & $\begin{array}{l}26 \mathrm{~S} \text { proteasome } \\
\text { regulatory subunit Rpn7 }\end{array}$ \\
\hline g932.t1 & ODA82425.1 & $\begin{array}{c}\operatorname{chr} 2 \\
6515072 . .6518106\end{array}$ & Swe2 > Swe3 & C1338T & $\begin{array}{c}\mathrm{Gln}(\mathrm{CAG}) 420 \mathrm{STOP} \\
\text { (TAG) }\end{array}$ & 984 & $\begin{array}{l}\text { Transcription factor } \\
\text { induced by hypoxia }\end{array}$ \\
\hline g3500.t1 & ODA80732.1 & $\begin{array}{c}\text { chr } 1 \\
2667080 . .2670892\end{array}$ & Swe2 > Swe3 & ins $209 \mathrm{C}$ & Premature stop & 1270 & $\begin{array}{l}\text { GTPase-activator protein } \\
\text { for Ras-like GTPase }\end{array}$ \\
\hline
\end{tabular}




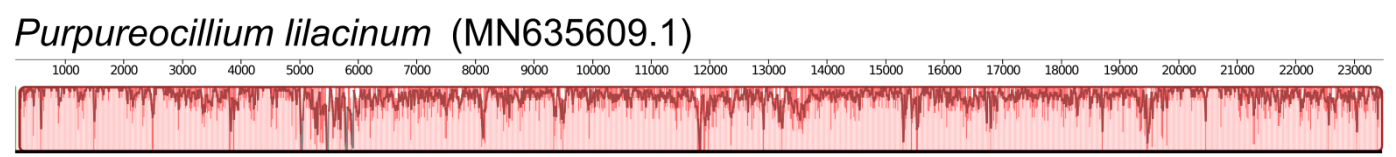

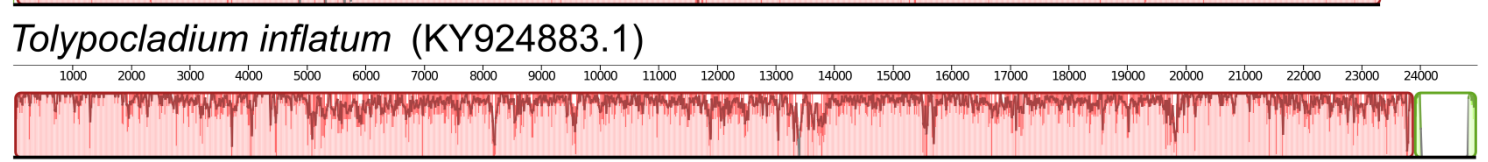

Tolypocladium cyclosporum (MN842262.1)

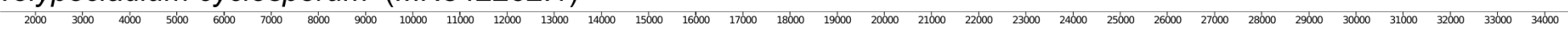

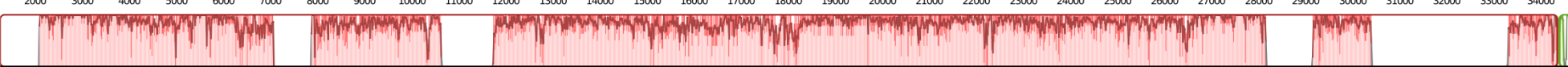

Drechmeria coniospora (Swe1, 2, 3)

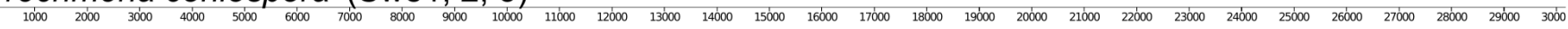

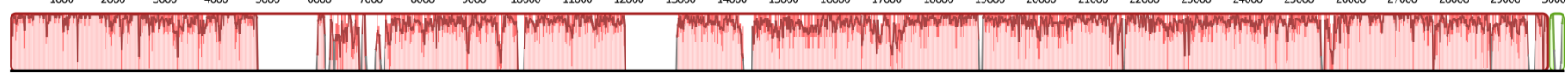

Supplementary Figure S1: Alignment of mitochondrial genomes from D. coniospora and 3 closely related fungi. For each species, a histogram of the overall sequence conservation (from 0 to $100 \%$ ) calculated using a sliding window of fixed size is shown under the genome coordinates (in $\mathrm{kb}$ ). The regions in red are syntenic and conserved across the four species, those in green correspond to sequences absent from P. lilacinum.

Locus 1

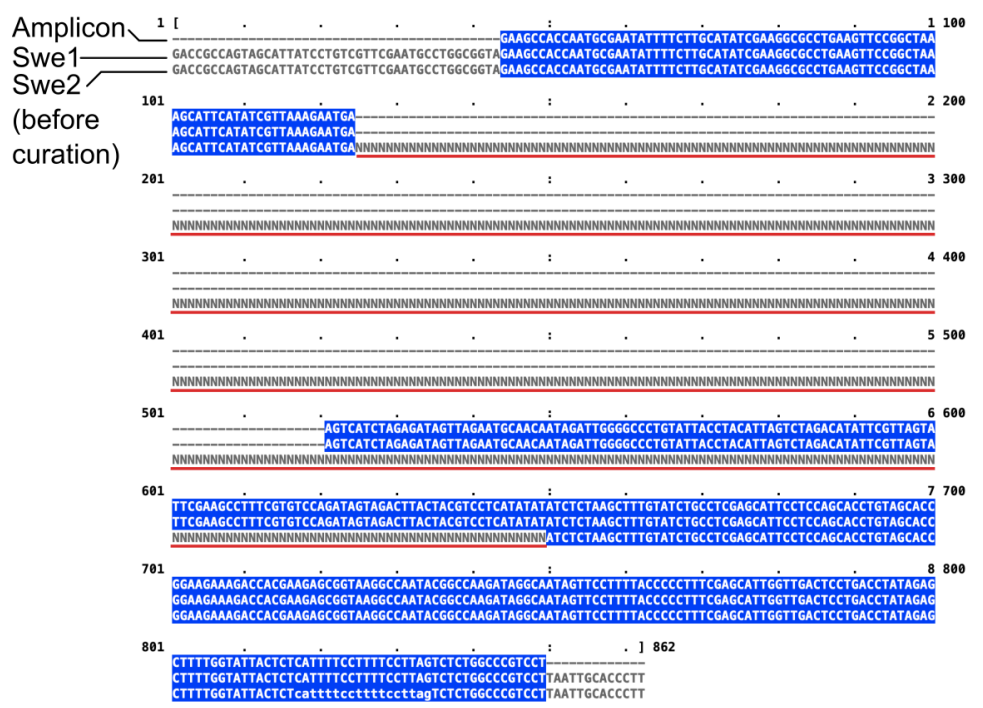

Locus 2

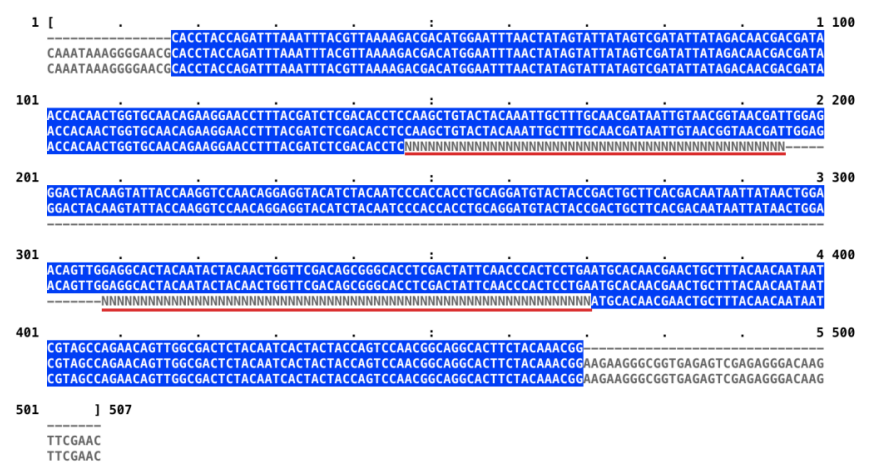

Supplementary Figure S2: Experimental validation of strategy to replace undetermined Swe2 sequences. Sequence alignments of 2 sequenced amplicons from Swe2, and the corresponding regions from the Swe1 and existing Swe2 genomic sequences. The blue highlights matching positions between the 3 sequences. The red lines indicate the stretches of underdetermined bases in the original Swe2 genome. Note, these regions were chosen as the corresponding sequence in Swe3 is identical to that in Swe1. The primers pairs used were GACCGCCAGTAGCATTATCC and AAGGGTGCAATTAAGGACGG for the left locus; CAAATAAAGGGGAACGCACC and GTTCGAACTTGTCCCTCTCG for the right. 
bioRxiv preprint doi: https://doi.org/10.1101/2021.09.01.457749; this version posted September 3, 2021. The copyright holder for this

preprint (which was not certified by peer review) is the author/funder, who has granted bioRxiv a license to display the preprint in perpetuity. It is made available under aCC-BY-NC-ND 4.0 International license.

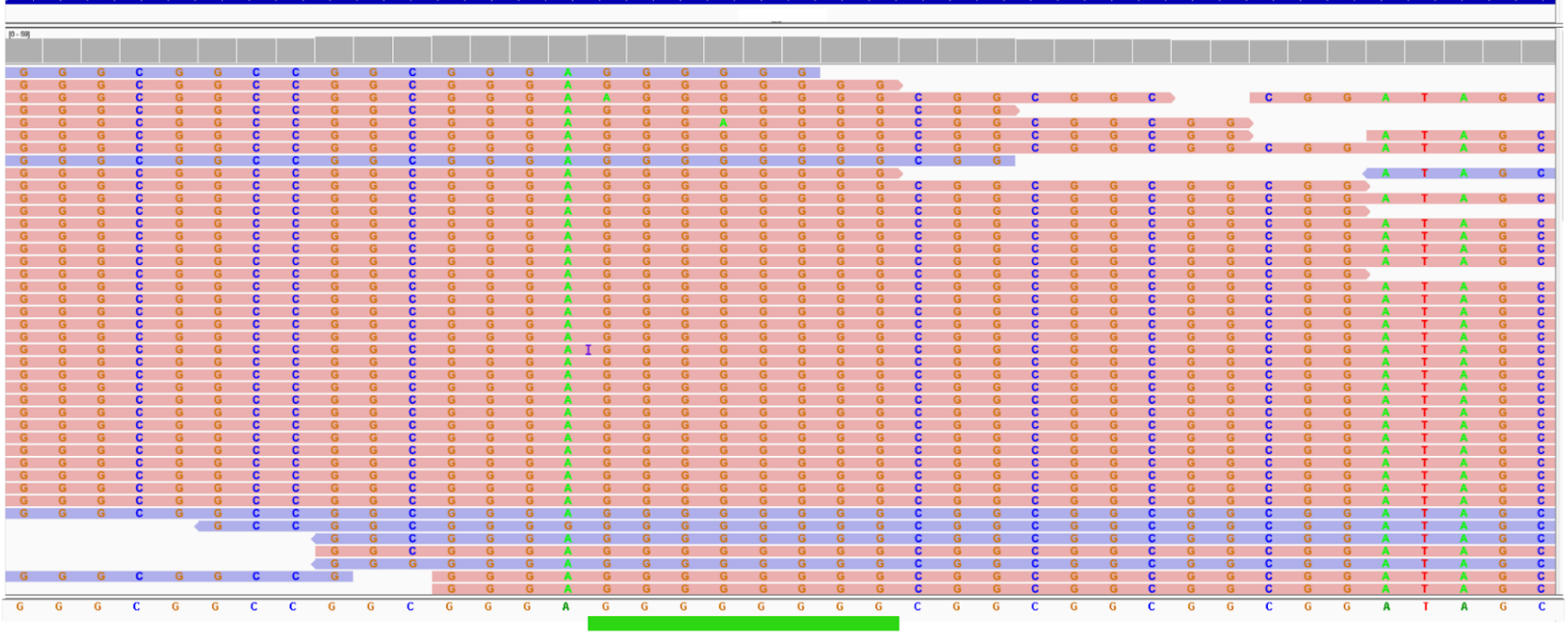

Swe3 chromosome 3: $7109562 . .7109603$

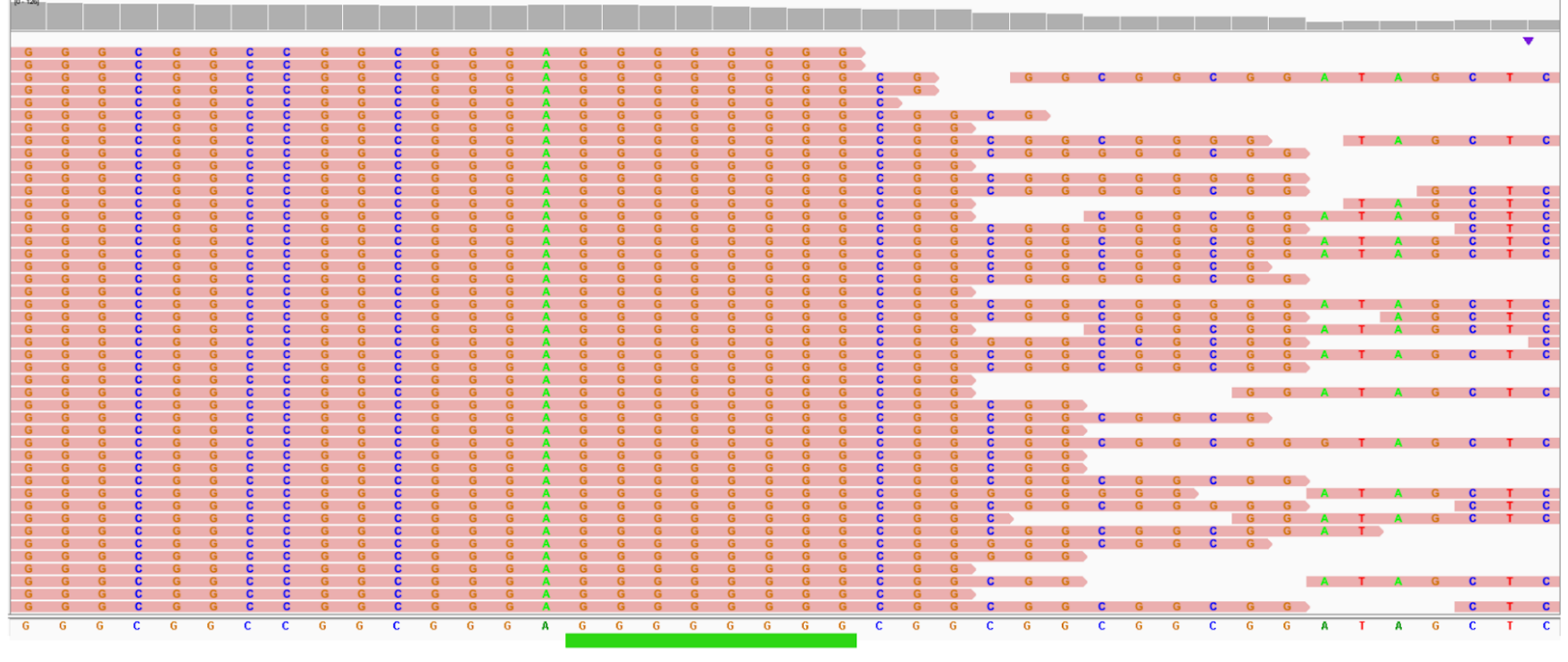

Swe1 chromosome 3: $7099070 . .7099100$

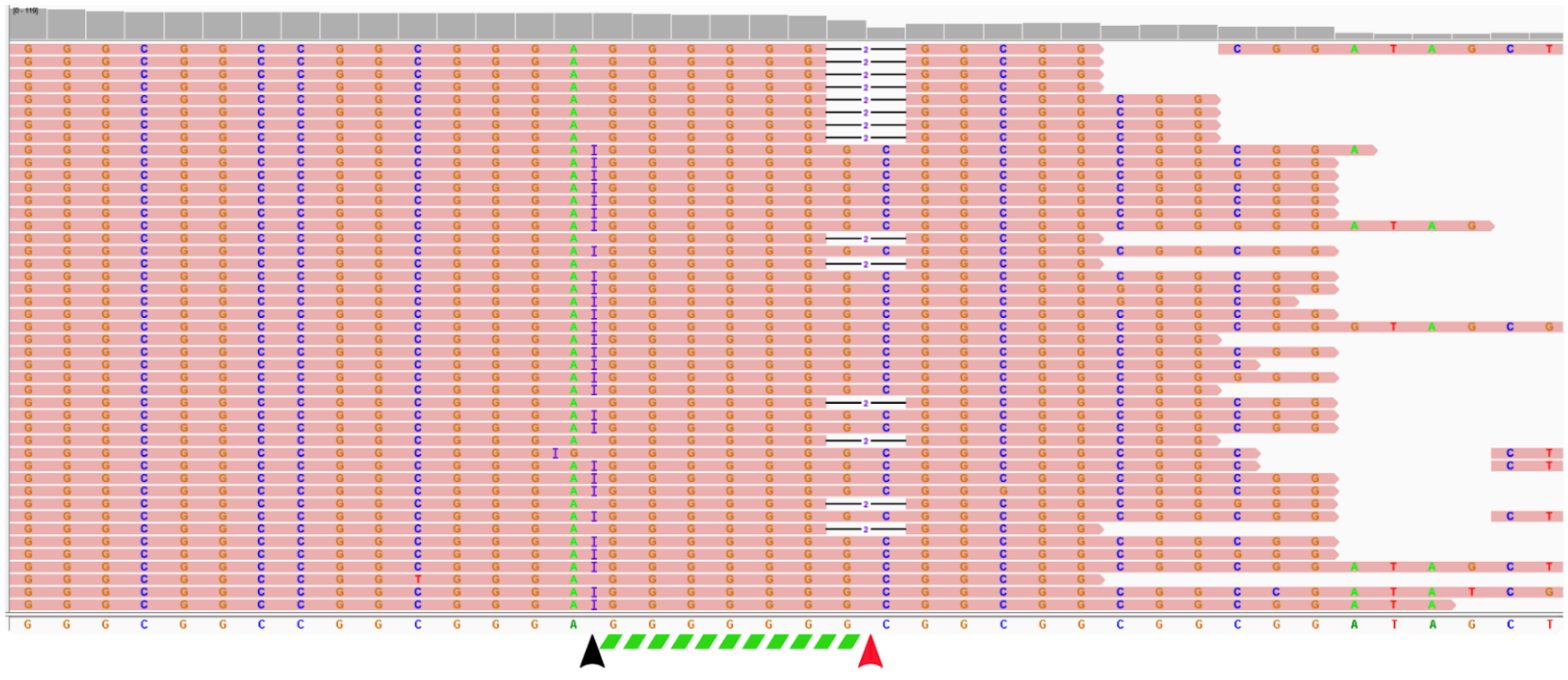


Supplementary Figure S3: Homopolymeric region bearing a residual sequence error.

Mapping of short DNA sequencing reads to the equivalent locus in the Swe2, Swe3 and Swe1 genomes, for which the respective genomic coordinates are indicated. A selection of the reads for each is represented, with their sequences in a salmon or light blue background, depending on their orientation. The sequence predicted for the locus, after polishing for Swe1 and Swe 3 (Courtine et al., 2020), is shown below the mapped reads in each panel. The green rectangles under the top and middle panels highlight a homopolymer of $8 \mathrm{Gs}$. This $8 \mathrm{G}$ sequence, supported by a large majority of short reads in all cases, has been incorrectly truncated to 7 Gs in Swe1, as highlighted by the dashed green rectangle. The black arrowhead marks the position where numerous reads have an extra $\mathrm{G}$ (an insertion as indicated by the blue I) that has not been taken into proper consideration, and the red arrowhead the highlights a position where numerous reads have been mismapped because of the tandem repetition of the sequence CGG, 3' to the homopolymeric sequence, resulting in the inference of 2 nucleotide deletions, with respect to the (erroneous) reference, as indicated by -2-. 
A

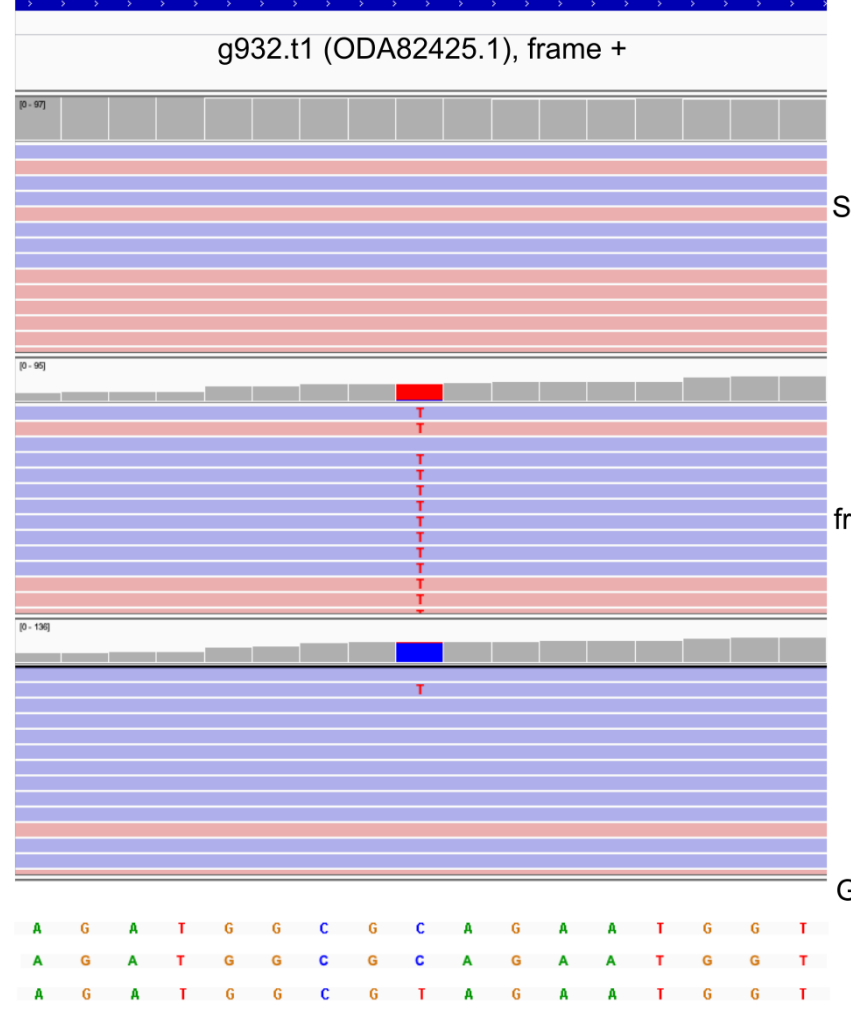

Swe2 genomic reads (SRR1810847)

RNAseq reads from Swe2 mycelium (SRR1930119)

RNAseq reads from Swe2 spore (SRR1930124)

Genomic sequences Swe1
Swe2
Swe3 B

\begin{tabular}{ccccc} 
Gene & Allele & Genomic reads & Mycelium RNAseq & Spores RNAseq \\
\hline \multirow{2}{*}{ g932.t1 } & Ref (C) & $91(99 \%)$ & $3(8 \%)$ & $59(92 \%)$ \\
& Alt (T) & $1(1 \%)$ & $34(92 \%)$ & $5(8 \%)$ \\
\hline \multirow{2}{*}{ g7915.t1 } & Ref (C) & $74(100 \%)$ & $5(3 \%)$ & $128(82 \%)$ \\
& Alt (A) & 0 & $144(96 \%)$ & $28(18 \%)$
\end{tabular}

Supplementary Figure S4: Examples of sequence heterogeneity captured by RNAseq. (A) Evidence at two sites for a disparity between the Swe2 genomic sequence and the sequence determined by transcriptome sequencing. Screen captures from IGV showing the mapping of genomic reads (top), and two RNAseq read sets from mycelia (middle) and spores (bottom). The boxes at the top of each panel represent the read coverage at each nucleotide position. They are coloured grey if $>95 \%$ of reads support the consensus sequence for the Swe 2 genome (shown below; identical to the corresponding sequence in the Swe1 genome). If an alternative nucleotide is supported by at least $5 \%$ of reads, the boxes are coloured proportionately, with the colours corresponding to those used for the different nucleotides in the genomic sequence shown below. Reads are represented in salmon or light blue, depending on their orientation. In those that do not match entirely the genomic sequence, non-consensus nucleotides are shown. For g7915.t1 (right), the gene is in the $3^{\prime}-5$ ' orientation, while the alleles are given for the 5'-3' sequence. (B) Summary of the number of reads supporting each allele in the 3 sets of reads. 
bioRxiv preprint doi: https://doi.org/10.1101/2021.09.01.457749; this version posted September 3, 2021. The copyright holder for this

preprint (which was not certified by peer review) is the author/funder, who has granted bioRxiv a license to display the preprint in perpetuity. It is made available under aCC-BY-NC-ND 4.0 International license.
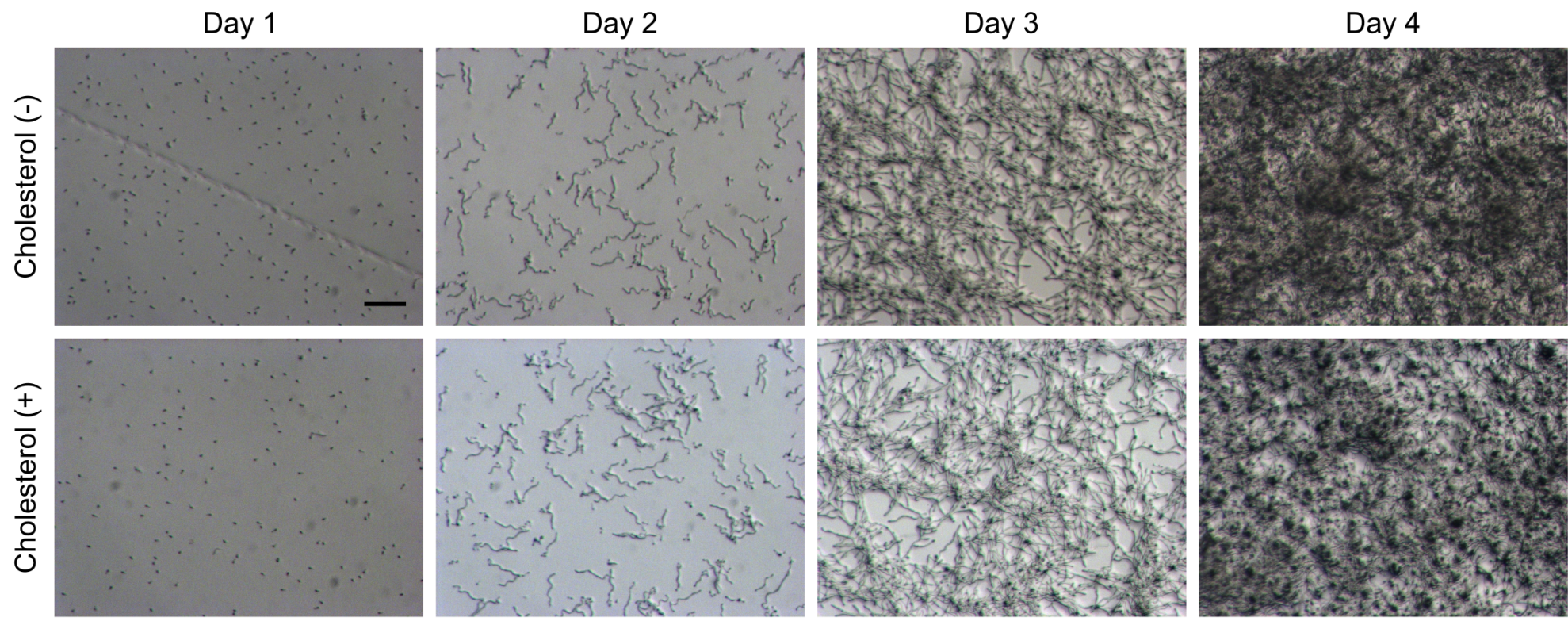

Supplementary Figure S5: Growth of a DcSrel mutant is not altered by cholesterol supplementation. Swe3 carries a null allele of DcSre1. Fungal growth on standard NGM plates $(+)$ or plates without (-) the normal $5 \mu \mathrm{g} / 1$ cholesterol supplementation was monitored at the indicated times. Scale $=100 \mu \mathrm{m}$. 
bioRxiv preprint doi: https://doi.org/10.1101/2021.09.01.457749; this version posted September 3, 2021. The copyright holder for this

preprint (which was not certified by peer review) is the author/funder, who has granted bioRxiv a license to display the preprint in perpetuity. It is made available under aCC-BY-NC-ND 4.0 International license.

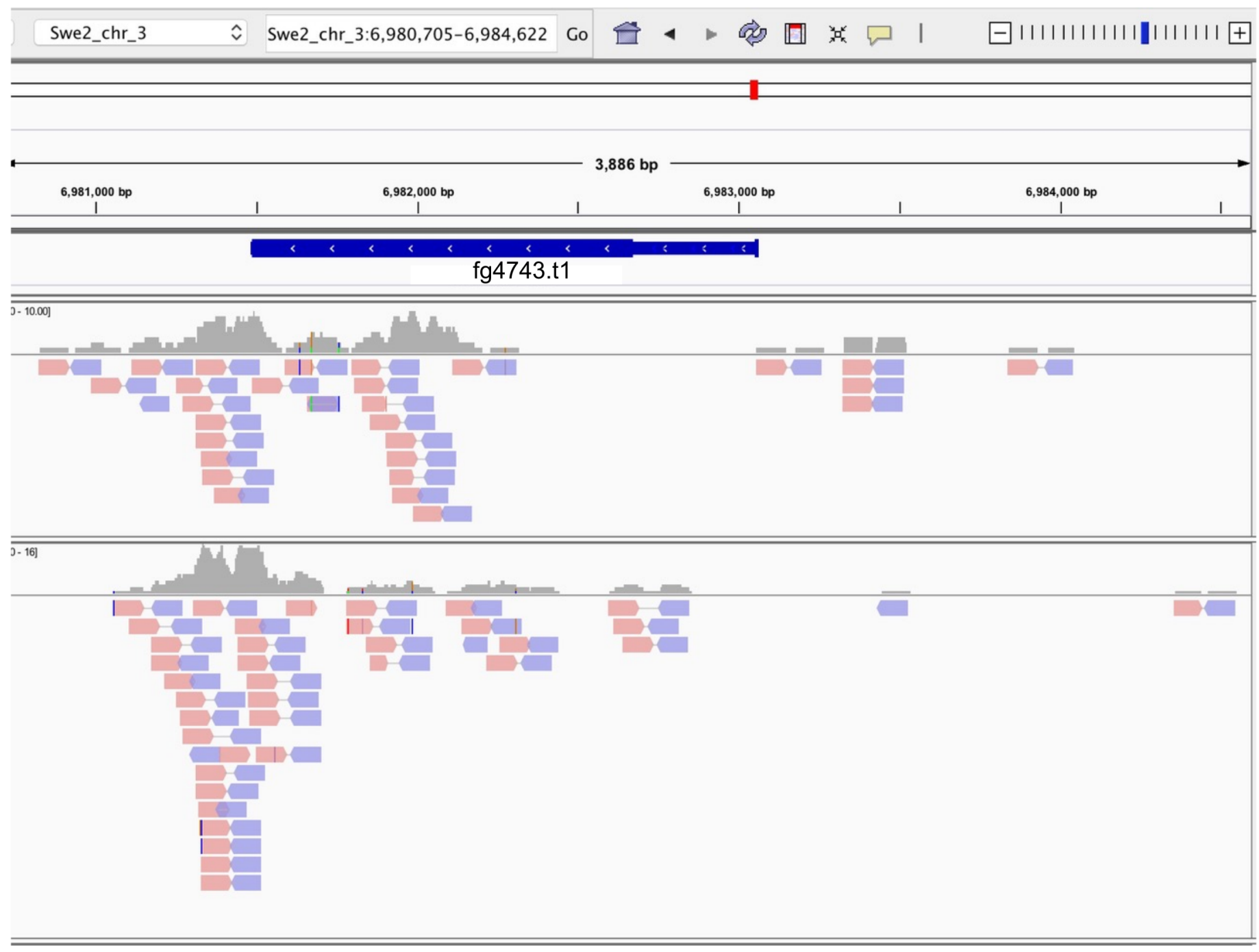

Supplementary Figure S6: Imperfect RNAseq support for the current gene model of fg4743. Screen capture from IGV showing the mapping of two RNAseq read sets from mycelia (top) and spores (bottom) at the fg4743 (ODA79924.1) locus. The boxes at the top of each panel represent the read coverage at each nucleotide position. They are coloured grey if $>95 \%$ of reads support the consensus sequence for the Swe2 genome. If an alternative nucleotide is supported by at least $5 \%$ of reads, the boxes are coloured proportionately, with the colours being the standard ones for the different nucleotides. Reads are represented in salmon or light blue, depending on their orientation, with coloured vertical lines indicating non-consensus nucleotides; paired reads are connected by a thin horizontal line. 
Supplementary Table 1: PCR tests used to genotype the $D$. coniospora Swe strains.

\begin{tabular}{|c|c|c|c|c|}
\hline $\begin{array}{l}\text { Strains to } \\
\text { differentiate }\end{array}$ & Description & Target & Primer id & Sequence \\
\hline \multirow{3}{*}{ Swe1, Swe2 } & \multirow{3}{*}{ Deletion in gene g1885.t1 (ODA83372.1) } & \multirow{3}{*}{ Chr. 2, g1885.t1 } & F1_g1885 & GTGGTCGACGAGGAACGC \\
\hline & & & F2_g1885 & CGGCTCAGTACAAAGCTACCC \\
\hline & & & R_g1885 & ACGACGTAGAAGAAGTCGCC \\
\hline \multirow{2}{*}{ Swe1, Swe2 } & \multirow{2}{*}{ SNP in gene g8020.t1 (ODA75964.1): A1230G } & \multirow{2}{*}{ Chr. 3, g8020.t1 } & F_g8020 & АССАССТАССАССТСТСGС \\
\hline & & & R_g8020 & GGCGACGATCTTGACGGG \\
\hline \multirow{2}{*}{ Swe1, Swe2 } & \multirow{2}{*}{ SNP in gene g3072.t1 (ODA80305.1): C490A } & \multirow{2}{*}{ Chr. 1, g3072.t1 } & F_g3072 & ACCAGACGTTACTCCCAAGC \\
\hline & & & R_g3072 & ACCCTAAAGTTGTCCCAGAAGC \\
\hline \multirow{2}{*}{ Swe2, Swe3 } & \multirow{2}{*}{ SNP in the gene g932.t1 (ODA82425.1): C1338T } & \multirow{2}{*}{ Chr. 2, g932.t1 } & F_g932 & AGTGCCCCAACAGGATTACC \\
\hline & & & R_g932 & ATGCGGTAGCCCATGAGATG \\
\hline \multirow{2}{*}{ Swe2, Swe3 } & \multirow{2}{*}{$\begin{array}{l}\text { One insertion in gene g3500.t1 (ODA80732.1): } \\
\text { 209insC }\end{array}$} & \multirow{2}{*}{ Chr. 1, g3500.t1 } & F_g3500 & CATCATGCAAGGACACGCC \\
\hline & & & R_g3500 & CTGGGAGAGATGGGGGAGG \\
\hline \multirow{2}{*}{ Swe2, Swe3 } & \multirow{2}{*}{ SNP in the gene g7471.t1 (ODA76724.1): G1486A } & \multirow{2}{*}{ Chr. 3, g7471.t1 } & F_g7471 & AAAAGACGGACTTTGGACGC \\
\hline & & & R_g7471 & GATTTTGTCGCTCGACTGGC \\
\hline Target & Primers & Strain & Amplicon (bp) & Read out \\
\hline \multirow{4}{*}{ g1885.t1 } & F1_g1885 + R_g1885 & Swe1 & 403 & \multirow{4}{*}{ Amplicon migration } \\
\hline & F1_g1885 + R_g1885 & Swe2 & 383 & \\
\hline & F2_g1885 + R_g1885 & Swe1 & 365 & \\
\hline & F2_g1885 + R_g1885 & Swe2 & 0 & \\
\hline g8020.t1 & F_g8020 + R_g8020 & Swe1 / Swe2 & 282 & Sequencing \\
\hline g3072.t1 & F_g3072 + R_g3072 & Swe1 / Swe2 & 289 & Sequencing \\
\hline g932.t1 & F_g932 + R_g932 & Swe2 / Swe3 & 300 & Restriction $(H h a l)+$ migration \\
\hline \multirow{2}{*}{ g3500.t1 } & F_g3500 + R_g3500 & Swe2 & 249 & \multirow{2}{*}{ Sequencing } \\
\hline & F_g3500 + R_g3500 & Swe3 & 250 & \\
\hline g7471.t1 & F_g7471 + R_g7471 & Swe2 / Swe3 & 295 & Sequencing \\
\hline
\end{tabular}


Supplementary table 2: Presence/absence of mitochondrial genes found in Swe2 compared to 3 closely related fungi mitogenomes

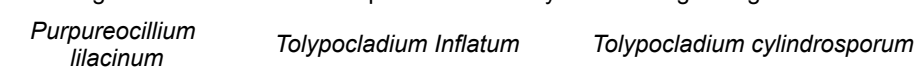

$\frac{10.1080 / 23802359}{2019.1699466 \text { (Li et al., }} \frac{10.1007 / \text { s00253-017- }}{8574-0 \text { (Zhang et al., }} \quad \frac{10.1080 / 23802359.2020 .1714495}{\text { (Zhang and Zhang 2020) }}$ 2020)

KY924883.1 (Zhang and Zhang 2020)

MN842262.1
Swe2

MFannot webserver https://megasun. bin/mfannot/mfannotInterface.pl

\begin{tabular}{|c|c|c|c|c|c|c|c|}
\hline & & & MN635609.1 & KY924883.1 & MN842262.1 & - & - \\
\hline \multirow{2}{*}{ rRNA genes } & small sub-unit & rns & ok & ok & ok & ok & ok \\
\hline & large sub-unit & $\mathrm{rnl}$ & ok & ok & ok (2 introns; rps3 and GIY) & ok & ok \\
\hline \multirow{15}{*}{$\begin{array}{l}\text { Protein-coding } \\
\text { genes }\end{array}$} & \multirow{3}{*}{ ATP synthase } & atp6 & ok & ok & ok & ok & ok \\
\hline & & atp8 & ok & ok & ok & ok & ok \\
\hline & & atp9 & ok & ok & ok (1 intron; GIY) & ok & ok \\
\hline & apocytochrome b & $\mathrm{cob}$ & ok & ok & ok (1 intron; GIY) & ok (1 intron; GIY) & ok (1 intron; GIY) \\
\hline & \multirow{3}{*}{$\begin{array}{l}\text { cytochrome } \\
\text { oxidase }\end{array}$} & $\operatorname{cox} 1$ & ok & ok & ok (2 introns; LAGLIDADG and GIY)) & ok (2 introns; LAGLIDADG and GIY) & ok (2 introns; LAGLIDADG and GIY) \\
\hline & & $\operatorname{cox} 2$ & ok & ok & ok & ok & ok \\
\hline & & $\operatorname{cox} 3$ & ok & ok & ok & ok & ok \\
\hline & \multirow{7}{*}{$\begin{array}{c}\text { NADH } \\
\text { dehydrogenase }\end{array}$} & nad1 & ok & ok & ok & ok & ok \\
\hline & & nad2 & ok & ok & ok & ok & ok \\
\hline & & nad3 & ok & ok & ok & ok & ok \\
\hline & & nad4 & ok & ok & ok & ok & ok \\
\hline & & nad4L & ok & ok & ok & ok & ok \\
\hline & & nad5 & ok & ok & ok & ok (1 intron;LAGLIDADG) & ok (1 intron; LAGLIDADG) \\
\hline & & nad6 & ok & ok & ok & ok & ok \\
\hline & rps-like protein & rps3 & ok & ok & ok & ok & ok \\
\hline \multirow{24}{*}{ tRNA genes } & \multicolumn{2}{|c|}{$\operatorname{trn} A(\operatorname{tgc})$} & ok & ok & ok & ok & ok \\
\hline & \multicolumn{2}{|c|}{$\operatorname{trnC}(\mathrm{gca})$} & absent & ok & ok & ok & ok \\
\hline & \multicolumn{2}{|c|}{$\operatorname{trnD}(\mathrm{gtc})$} & ok & ok & ok & ok & ok \\
\hline & \multicolumn{2}{|c|}{$\operatorname{trnE}(\mathrm{ttc})$} & ok & ok & ok & ok & ok \\
\hline & \multicolumn{2}{|c|}{$\operatorname{trnF}$ (gaa) } & ok & ok & ok & ok & ok \\
\hline & \multicolumn{2}{|c|}{$\operatorname{trnG(acc)}$} & absent & absent & ok & absent & absent \\
\hline & \multicolumn{2}{|c|}{$\operatorname{trnG}(\mathrm{tcc})$} & ok & ok & ok & ok & ok \\
\hline & \multicolumn{2}{|c|}{$\operatorname{trnH}(\mathrm{gtg})$} & ok & ok & ok & ok & ok \\
\hline & \multicolumn{2}{|c|}{ trnl(gat) } & ok & ok & ok & ok & ok \\
\hline & \multicolumn{2}{|c|}{$\operatorname{trnK}(\mathrm{ttt})$} & ok & ok & ok & ok & ok \\
\hline & \multicolumn{2}{|c|}{$\operatorname{trnL}(\operatorname{tag})$} & ok & ok & ok & ok & ok \\
\hline & \multicolumn{2}{|c|}{$\operatorname{trnL}$ (taa) } & ok & ok & ok & ok & ok \\
\hline & \multicolumn{2}{|c|}{$\operatorname{trnM}$ (cat) } & 3 copies & 3 copies & 3 copies & 3 copies & 3 copies \\
\hline & \multicolumn{2}{|c|}{$\operatorname{trnN(gtt)}$} & ok & ok & ok & ok & ok \\
\hline & \multicolumn{2}{|c|}{$\operatorname{trnP}(\operatorname{tgg})$} & ok & ok & ok & ok & ok \\
\hline & \multicolumn{2}{|c|}{$\operatorname{trn} Q(\operatorname{ttg})$} & ok & ok & ok & ok & ok \\
\hline & \multicolumn{2}{|c|}{$\operatorname{trnR}(\mathrm{acg})$} & ok & ok & ok & ok & ok \\
\hline & \multicolumn{2}{|c|}{$\operatorname{trnR}(\mathrm{tct})$} & ok & ok & ok & ok & ok \\
\hline & $\operatorname{trnS}(\mathrm{t}$ & & ok & ok & ok & ok & ok \\
\hline & $\operatorname{trnS}(\mathrm{g}$ & & ok & ok & ok & ok & ok \\
\hline & $\operatorname{trnT}(\mathrm{t}$ & & absent & ok & ok & ok & ok \\
\hline & $\operatorname{trnV}(\mathrm{t}$ & & absent & ok & ok & ok & ok \\
\hline & $\operatorname{trnW}(\mathrm{t}$ & & ok & ok & ok & ok & ok \\
\hline & $\operatorname{trn} Y(\mathrm{c}$ & & ok & ok & ok & ok & ok \\
\hline
\end{tabular}


bioRxiv preprint doi: https://doi.org/10.1101/2021.09.01.457749; this version posted September 3, 2021. The copyright holder for this preprint (which was not certified by peer review) is the author/funder, who has granted bioRxiv a license to display the preprint in perpetuity. It is made available under aCC-BY-NC-ND 4.0 International license.

Supplementary table 3: Status in the new assembly of Swe2 scaffolds that had not previously been incoprorated into the genome assembly

\begin{tabular}{|c|c|c|c|c|c|}
\hline Swe2 scaffold & length (nt) & presence of gene? & Insert in Swe2 & Length after trimming & remark \\
\hline JYHR01000012.1 & 173380 & yes & chromosome 3 & 160167 & \\
\hline JYHR01000013.1 & 54712 & yes & chromosome 1 & 50350 & \\
\hline JYHR01000014.1 & 48392 & yes & chromosome 3 & 43976 & \\
\hline JYHR01000015.1 & 29422 & yes & chromosome 1 & 28782 & \\
\hline JYHR01000016.1 & 28571 & yes & chromosome 3 & 28571 & \\
\hline JYHR01000017.1 & 28080 & yes & chromosome 3 & 21992 & \\
\hline JYHR01000018.1 & 27206 & yes & chromosome 3 & 27206 & \\
\hline JYHR01000019.1 & 26919 & yes & chromosome 3 & 26919 & \\
\hline JYHR01000020.1 & 26539 & yes & chromosome 2 & 26539 & \\
\hline JYHR01000021.1 & 23828 & yes & mitochondria & NA & \\
\hline JYHR01000022.1 & 23058 & no & NA & NA & \\
\hline JYHR01000023.1 & 22641 & yes & chromosome 3 & 22641 & \\
\hline JYHR01000024.1 & 20036 & yes & chromosome 3 & 16817 & \\
\hline JYHR01000025.1 & 18657 & yes & chromosome 3 & 18657 & \\
\hline JYHR01000026.1 & 16902 & yes & chromosome 3 & 16902 & \\
\hline JYHR01000027.1 & 16052 & yes & chromosome 3 & 16052 & \\
\hline JYHR01000028.1 & 14597 & no & NA & NA & \\
\hline JYHR01000029.1 & 14514 & yes & chromosome 3 & 14514 & \\
\hline JYHR01000030.1 & 14170 & yes & chromosome 2 & 14170 & \\
\hline JYHR01000031.1 & 14066 & yes & chromosome 3 & 14066 & \\
\hline JYHR01000032.1 & 9307 & yes & chromosome 3 & 9307 & \\
\hline JYHR01000033.1 & 9128 & no & NA & NA & \\
\hline JYHR01000034.1 & 8345 & no & NA & NA & \\
\hline JYHR01000035.1 & 8253 & yes & chromosome 3 & 8253 & \\
\hline JYHR01000036.1 & 6725 & no & NA & NA & \\
\hline JYHR01000037.1 & 6689 & no & NA & NA & \\
\hline JYHR01000038.1 & 6421 & yes & chromosome 3 & 6421 & \\
\hline JYHR01000039.1 & 6407 & yes & NA & NA & Identical to JYHR01000038.1 \\
\hline JYHR01000040.1 & 5655 & no & NA & NA & \\
\hline JYHR01000041.1 & 5653 & no & NA & NA & \\
\hline JYHR01000042.1 & 5624 & no & NA & NA & \\
\hline JYHR01000043.1 & 5249 & yes & NA & NA & Already present in the genome, assembly duplication \\
\hline JYHR01000044.1 & 5211 & yes & chromosome 3 & 5211 & \\
\hline JYHR01000045.1 & 4839 & no & NA & NA & \\
\hline JYHR01000046.1 & 3936 & no & NA & NA & \\
\hline JYHR01000047.1 & 3817 & yes & NA & NA & Already present in the genome, assembly duplication \\
\hline JYHR01000048.1 & 3440 & no & NA & NA & \\
\hline JYHR01000049.1 & 2917 & no & NA & NA & \\
\hline JYHR01000050.1 & 2571 & no & NA & NA & \\
\hline JYHR01000051.1 & 2487 & yes & chromosome 3 & 2487 & \\
\hline JYHR01000052.1 & 2111 & no & NA & NA & \\
\hline JYHR01000053.1 & 2040 & no & NA & NA & \\
\hline JYHR01000054.1 & 1554 & no & NA & NA & \\
\hline JYHR01000055.1 & 1460 & no & NA & NA & \\
\hline JYHR01000056.1 & 1434 & no & NA & NA & \\
\hline JYHR01000057.1 & 1343 & no & NA & NA & \\
\hline JYHR01000058.1 & 1318 & no & NA & NA & \\
\hline JYHR01000059.1 & 1285 & no & NA & NA & \\
\hline JYHR01000060.1 & 1146 & no & NA & NA & \\
\hline JYHR01000061.1 & 1041 & no & NA & NA & \\
\hline JYHR01000062.1 & 932 & no & NA & NA & \\
\hline JYHR01000063.1 & 902 & no & NA & NA & \\
\hline JYHR01000064.1 & 891 & no & NA & NA & \\
\hline JYHR01000065.1 & 825 & no & NA & NA & \\
\hline JYHR01000066.1 & 814 & no & NA & NA & \\
\hline JYHR01000067.1 & 812 & no & NA & NA & \\
\hline JYHR01000068.1 & 757 & no & NA & NA & \\
\hline JYHR01000069.1 & 722 & no & NA & NA & \\
\hline JYHR01000070.1 & 701 & no & NA & NA & \\
\hline JYHR01000071.1 & 636 & no & NA & NA & \\
\hline JYHR01000072.1 & 584 & no & NA & NA & \\
\hline JYHR01000073.1 & 556 & no & NA & NA & \\
\hline JYHR01000074.1 & 536 & no & NA & NA & \\
\hline JYHR01000075.1 & 505 & no & NA & NA & \\
\hline
\end{tabular}


bioRxiv preprint doi: https://doi.org/10.1101/2021.09.01.457749; this version posted September 3, 2021. The copyright holder for this

preprint (which was not certified by peer review) is the author/funder, who has granted bioRxiv a license to display the preprint in perpetuity. It is made available under aCC-BY-NC-ND 4.0 International license.

Supplementary table 3 (continued): Swe2 assembly statistics

$\begin{array}{lcc} & \text { Chromosomes } & \text { Unplaced scaffolds } \\ \text { Genome size (Mb) } & 31.75 & 0.128 \\ \text { Sequences } & 3+\mathrm{MT} & 38 \\ \text { GC content }(\%) & 55.25 & 44.38 \\ \text { \% of unknowns (Ns) } & 0.11 & 3.8 \\ \begin{array}{l}\text { No. predicted protein- } \\ \text { coding genes }\end{array} & 8702 & 0\end{array}$


bioRxiv preprint doi: https://doi.org/10.1101/2021.09.01.457749; this version posted September 3, 2021. The copyright holder for this preprint (which was not certified by peer review) is the author/funder, who has granted bioRxiv a license to display the preprint in perpetuity. It is made available under aCC-BY-NC-ND 4.0 International license.

Supplementary table 4: ANI values for all pairs of Swe genomes from pyANI v0.29.

Sequences were aligned with MUMmer (ANIm) or BLAST+ (ANIb). Tetranuccleotides correlations represent similarity with alignement-free method.

\begin{tabular}{|c|c|c|c|c|}
\hline Measure & Query strain & Swe1 & Swe2 & Swe3 \\
\hline \multirow{3}{*}{ ANIm } & Swe1 & 100 & 99.9052 & 99.9896 \\
\hline & Swe2 & 99.9052 & 100 & 99.9060 \\
\hline & Swe3 & 99.9896 & 99.9060 & 100 \\
\hline \multirow{3}{*}{ ANIb } & Swe1 & 100 & 99.7694 & 99.9901 \\
\hline & Swe2 & 99.9155 & 100 & 99.9154 \\
\hline & Swe3 & 99.9820 & 99.7608 & 100 \\
\hline \multirow{3}{*}{$\begin{array}{l}\text { Tetranuccleotides } \\
\text { correlations }\end{array}$} & Swe1 & 100 & 99.9709 & 99.9971 \\
\hline & Swe2 & 99.9709 & 100 & 99.9550 \\
\hline & Swe3 & 99.9971 & 99.9550 & 100 \\
\hline
\end{tabular}


Supplementary Table 5: Results of BLAST searches of Dan2 sexual reproduction-related proteins

\begin{tabular}{|c|c|c|c|c|c|c|c|c|}
\hline Query & Query ID & Query size (aa) & Best BLASTP hit in Swe2 & Score & $\%$ ID & $\begin{array}{l}\text { Alignment } \\
\text { length (aa) }\end{array}$ & $\begin{array}{l}\text { Query coverage } \\
(\%)\end{array}$ & Comment \\
\hline MAT1-1-1 & KYK59754.1 & 370 & - & - & - & - & - & \\
\hline MAT1-1-2 & KYK59755.1 & 353 & - & - & - & - & - & \\
\hline MAT1-1-3 & KYK59756.1 & 166 & ODA81607.1 & 71 & 40 & 75 & 45 & Alignment is restricted to the protein domain (HMG-box - PF00505) \\
\hline RIP - rid1 & KYK59907.1 & 646 & ODA78704.1 & 776 & 91 & 416 & 64 & \\
\hline RIP - dim-2 & KYK56049.1 & 377 & ODA76538.1 & 598 & 86.4 & 397 & 100 & \\
\hline Late sexual development protein & KYK59150.1 & 355 & ODA77900.1 & 706 & 99.72 & 355 & 100 & \\
\hline Heterokaryon incompatibility & KYK58811.1 & 804 & ODA84177.1 & 1630 & 98.88 & 804 & 100 & \\
\hline Heterokaryon incompatibility & KYK56754.1 & 938 & ODA78419.1 & 1898 & 99.68 & 938 & 100 & \\
\hline Heterokaryon incompatibility & KYK56328.1 & 752 & ODA76785.1 & 1506 & 99.73 & 732 & 97 & \\
\hline Heterokaryon incompatibility - putative & KYK55209.1 & 749 & ODA82169.1 & 1546 & 99.73 & 749 & 100 & \\
\hline
\end{tabular}

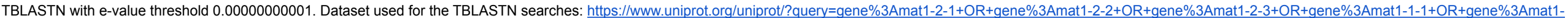
1-2+OR+gene\%3Amat1-1-3+\&sort=score

\begin{tabular}{|c|c|c|c|c|c|}
\hline Protein of interest & Target & Best HSP (TBLASTN) & Best HSP localization & $\begin{array}{l}\text { Best Query ID } \\
\text { (UniProt ID) }\end{array}$ & Comment \\
\hline MAT1-1-1 & Swe2 & no hit & & & \\
\hline MAT1-1-2 & Swe2 & no hit & & & \\
\hline MAT1-1-3 & Swe2 & ODA78559.1 & Chr. 1 & A7KPA5_COCPO & Querry does not have the required protein domain (HMG-box - PF00505) \\
\hline MAT1-2-1 & Swe2 & not hit & Chr. 1 & V9LW71_9HYPO & \\
\hline MAT1-2-2 & Swe2 & ODA81607.1 & Chr. 2 & AOA2K8C394_9PEZI & Alignment is restricted to the protein domain (HMG-box - PF00505) \\
\hline MAT1-2-3 & Swe2 & not hit & & & \\
\hline MAT1-1-1 & Dan2 & KYK59754.1 & Chr. 1 (СM004174.1) & U3N6X4_TOLIN & Presence of the protein domain "Mating-type protein MAT alpha 1 HMG-box" (PF04769) \\
\hline MAT1-1-2 & Dan2 & KYK59755.1 & Chr. 1 (CM004174.1) & Q1MVS6_TOLIN & Presence of the protein domain "Mating type protein 1-1-2" (PF17043) \\
\hline \multirow{2}{*}{ MAT1-1-3 } & \multirow{2}{*}{ Dan2 } & KYK59757.1 & Chr. 1 (СM004174.1) & A7KPA5_COCPO & Querry does not have the required protein domain (HMG-box - PF00505) \\
\hline & & KYK59756.1 & Chr. 1 (СM004174.1) & Q1MVS7̄_TOLIN & Presence of of the protein domain "HMG-box" (PF00505) \\
\hline MAT1-2-1 & Dan2 & KYK55799.1 & Chr. 3 (СM004176.1) & K4H8Z2_9HELO & Alignment is restricted to the protein domain (HMG-box - PF00505) \\
\hline MAT1-2-2 & Dan2 & KYK55799.1 & Chr. 3 (СM004176.1) & A0A2K8C394_9PEZI & Alignment is restricted to the protein domain (HMG-box - PF00505) \\
\hline
\end{tabular}

